NBER WORKING PAPER SERIES

\title{
COUNTERFEITERS: FOES OR FRIENDS? HOW DO COUNTERFEITS AFFECT DIFFERENT PRODUCT QUALITY TIERS?
}

\author{
Yi Qian \\ Working Paper 16785 \\ http://www.nber.org/papers/w16785 \\ NATIONAL BUREAU OF ECONOMIC RESEARCH \\ 1050 Massachusetts Avenue \\ Cambridge, MA 02138 \\ February 2011
}

I warmly acknowledge support from Kauffman Foundation grants. I am grateful to Josh Lerner, Eric Anderson, Philippe Aghion, Meghan Busse, Shane Greenstein, Angela Lee, Jin Li, Keith Maskus, Ivan Png, Scott Stern, Catherine Tucker, K. Sudhir, and Florian Zettlemeyer for helpful discussions; and to seminar participants at the Kellogg School of Management, Yale School of Management, University of Colorado, and Quantitative Marketing and Economics conference for comments. I thank Dr. Ting Zhu for sharing eBay data. I thank Gina Buonaguro, Maja Kos, and Sachin Waikar for copy-editing. Cooperation from the Chinese Quality and Technology Supervision Bureau (QTSB) and the companies I interviewed and surveyed is gratefully acknowledged. The results in this paper do not necessarily represent the views of QTSB or NBER.

NBER working papers are circulated for discussion and comment purposes. They have not been peerreviewed or been subject to the review by the NBER Board of Directors that accompanies official NBER publications.

(C) 2011 by Yi Qian. All rights reserved. Short sections of text, not to exceed two paragraphs, may be quoted without explicit permission provided that full credit, including $\odot$ notice, is given to the source. 
Counterfeiters: Foes or Friends? How Do Counterfeits Affect Different Product Quality Tiers?

Yi Qian

NBER Working Paper No. 16785

February 2011, Revised September 2013

JEL No. L25,L26,L6

\begin{abstract}
$\underline{\text { ABSTRACT }}$
A key concern about counterfeits and weak intellectual property protection is that they may hamper innovation by displacing legitimate sales. This paper combines a natural policy experiment with randomized lab experiments to estimate the heterogeneous impacts of counterfeiting on the sales and consumer purchase intent related to branded products of various quality levels. I collect new product-line-level panel data (1993-2004) on Chinese shoe companies. I identify heterogeneous effects of counterfeit entry on sales of authentic products of three quality tiers, finding that counterfeits have both advertising effects for a brand and substitution effects for authentic products, additionally the effects linger for some years. The advertising effect dominates the substitution effect for highend authentic-product sales, and the substitution effect outweighs the advertising effect for low-end product sales. The positive effect of counterfeits is most pronounced for high-fashion products (such as women's high-leg boots and dress shoes), for shoes tailored to young customers, and for high-end products of brands not yet well-known at the time of counterfeiter entry.
\end{abstract}

Yi Qian

Department of Marketing

Kellogg School of Management

Northwestern University

2001 Sheridan Road

Evanston, IL 60208

and NBER

yiqian@kellogg.northwestern.edu 


\section{INTRODUCTION}

Counterfeits are illegal products that infringe upon others' brands. They affect many industries and, by impacting the sales of authentic products, can have a large influence on incentives for brand owners to innovate. While counterfeits worry firms in general, the effects of counterfeit products may be heterogeneous, especially for different product types and quality tiers, as well as for brands at different life stages. Very few studies have examined the impacts of counterfeits directly. Grossman and Shapiro (1988a,b), for example, theorize about the implications of counterfeits for international trade. Qian (2008) offers the first econometric study of the average treatment effects of counterfeiting on authenticproduct differentiation and self-enforcement expenditures. While this small body of research is helpful, in order to effectively guide priorities for and directions of innovation and enforcement strategies, it is crucial to understand the sales impacts of counterfeits on authentic products of different types and quality tiers and on brands of different natures and life stages. However, the extant literature has left this topic largely unexplored, due in part to insufficient data. This study fills the void by investigating the specific sales impacts of counterfeits through field and experimental methods, including how product quality, product type, brand age, and brand famousness mediate these effects. Such sales-related findings go well beyond the general impacts of counterfeiting on brands' marketing norms, shedding much-needed light on potential incentives and directions for innovation and enforcement, including academic, managerial, and policy-related implications.

As compared to the previous paper, this study tackles a new research question, collects new data, and combines field studies with experiments. ${ }^{1}$ Its findings that counterfeits could have positive spillover effects on authentic sales are surprising at first sight yet shed new light on the literature. In the academic and managerial domains, this paper contributes to the growing literature that debates the assumed negative impact of counterfeits on authentic-product sales. While conventional wisdom suggests counterfeits will damage sales of authentic products through a substitution effect, Gosline (2009, 2010) shows through ethnographic research that some consumers use counterfeits as "trial versions" of high-end products and that more than $40 \%$ of those who purchased counterfeit purses eventually bought the real branded handbags. A stream of literature on online piracy has debated the effect of filesharing on original music sales in recent years; Liebowitz (2006) and Oberholzer-Gee and Strumpf

\footnotetext{
${ }^{1}$ The consistent results from the lab experiments in the U.S. demonstrate that the findings in the field panel data have implications beyond China.
} 
(2009) provide excellent surveys of this topic. While several empirical studies point to a negative effect of piracy and filesharing (Hui and Png 2003, Liebowitz 2006, Hong 2008), Oberholzer-Gee and Strumpf conclude that these activities actually have a positive effect, based on a uniquely matched dataset of music downloads and purchases. Along the same lines, Mortimer et al. (2010) find that illegitimate redistribution of digital goods increases revenue from non-digital complementary products, notably live performances. At the consumer level, Rob and Waldfogel (2006) conduct surveys of undergraduate students and find that although the average drop in album purchases due to downloading was $\$ 0.2$, consumer surplus increased due to the lower prices.

Illegal imitation also can have other positive effects on authentic-product sales. A commonly cited mechanism is network effects, where the consumer utility of a product is an increasing function in the size of the user base. This argument has been made frequently for software and book copyright cases (Takeyama 1991, Conner and Rumelt 1991, Khan 2004). Others suggest that imitation could serve as a signal for the original product's or idea's high quality (Castro et al. 2008, Biais and Perotti 2008), driving positive consumer attention. Such mechanisms speak to the positive, advertising effect of counterfeits. Yet existing studies collectively have not provided generalizable guidance for addressing the sales effects of counterfeits. Thus, understanding the heterogeneous effects of counterfeits on product and brand types will help to paint a more complete picture of counterfeits' impact as well as provide more specific direction for guidance.

Evidence for heterogeneous impacts of counterfeiting across product and brand attributes also will help guide priorities for intellectual property rights (IPR) enforcement policy. As the authors of a recent World Intellectual Property Organization study comment, "Governments are invariably resource constrained and completely eradicating violations of IPR law - like violations of other types of law - is out of reach for even the best-resourced states" (Fink et al. 2010). Moreover, while advocates of IPR promote its innovation-stimulating effects and their subsequent positive economic implications, these effects have been shown to be rather limited (Lerner 2009), with a generalizable conditional importance of patents only in countries with advanced education and development (Qian 2007, Kyle and McGahan 2011). The debate over IPR resulted in the TRIPs (Trade-Related Intellectual Property) negotiations, which were motivated largely by the desire to reduce trade in counterfeit goods. This study therefore contributes to the broader literature on how firm responses to their legal environment could have important moderating effects on the impact of IPR protection (Zhao 2006, Mortimer 2010).

One major methodological constraint for any empirical study of counterfeits (and of underground economics in general) is the illicit nature of the items or activities of focus (Thursby et al. 1991), which can make them difficult to observe at any level of detail in most settings. Footwear is 
a common target for counterfeiters. Of the $\$ 260$ million in counterfeit goods seized by U.S. Customs and Border Protection in 2009, footwear accounted for 40\%. In fact, counterfeit footwear has topped the seizure list for four years (Schmidle 2010). Due to severe counterfeiting infringements, the Chinese footwear sector in particular has had strong incentive to investigate the impacts of counterfeiters. In this study, I gather internal and external data on Chinese shoe brands to analyze the effects of counterfeiting on sales of products representing different quality tiers. I extend the brand-level panel data significantly to include footwear product-line details within each of 31 brands (including Chinese national brands and multinational brands operating in China), ${ }^{2}$ and, for the first time, obtain product-line-level sales data from 1993-2004. I also introduce a new IV (instrumental variable) to address the endogeneity of counterfeiting: the preexisting ties between brand and product-line managers and enforcement officials based on their biographic matches. This work accordingly identifies the heterogeneous effects of counterfeits on sales of authentic products of different types and at different quality tiers, as well as of brands at different life stages, along with charting the longer-term effects of counterfeits by quality tier. Detection of these heterogeneous effects sheds light on the mechanisms underlying counterfeiting effects and generates implications for the multiple domains discussed above.

With regard to the methodology, I disentangle the separate effects of counterfeiting by quality tier within a brand portfolio and by life stage of a brand. Within each type of brand and each type of class of products, I separately identify the counterfeiting effects at the quality-tier level through the difference-in-difference-in-difference simultaneous equation estimations. Moreover, combining field and experimental data generates insights at both the aggregated market level and the individual sampled consumer level. I leverage IV strategy to identify occasions in which counterfeiters enter the market because of exogenous policy shocks that are unrelated to the brand's sales prospects - "randomized" entry - to infer entry impacts. Analysis of the field data shows that counterfeits have both negative substitution and positive spillover effects on authentic-product sales: The net effect is positive for high-end authentic products and negative for low-end authentic products, even within the same brand. Furthermore, the positive marginal effects of counterfeits on authentic-product sales is more pronounced for high-fashion products (including dress shoes for men and women and women's high-leg boots), for shoes tailored to young customers, and for high-end shoes of newer brands that are not well-known at the time of counterfeiter entry or that do not own multiple sub-brands.

The findings suggest that counterfeiters can be both friends with and foes of authentic pro-

\footnotetext{
${ }^{2}$ Most footwear brands in China are concentrated in the leather and sports shoe subsector, which has annual sales of approximately US\$6 billion. Some Chinese brands (e.g., Li-ning, Anta) hold Chinese market shares nearly as large as that of Nike.
} 
ducers and that brands could optimize their self-enforcement efforts using insights from this study, including those related to the timing of counterfeit-related enforcement. This was exactly Microsoft's strategy in China, as Bill Gates told an audience at the University of Washington: "Although about 3 million computers get sold every year in China, people don't pay for the software. Someday they will, though. And as long as they're going to steal it, we want them to steal ours. They get sort of addicted, and then we'll somehow figure out how to collect sometime in the next decade" (Piller 2006). Only after the majority of Chinese consumers were "locked into" Microsoft products did the company engage in strict enforcement campaigns with the government to crack down on piracy and force the Chinese market to adopt legitimate Microsoft software. By that point, Linux was far less of a competitor for Microsoft in China than in the U.S. As discussed later, the heterogeneous sales impacts of counterfeits on different product lines yield additional managerial insights related to the optimal level of enforcement across the product lines within each brand, including the implications of counterfeits far inferior in quality to their authentic counterparts. For instance, brands need not concern themselves too much with counterfeits that have a wide quality gap below their authentic counterparts, as these counterparts capture a very different customer segment that would not purchase the authentic product anyway. Brands can also devote relatively fewer enforcement resources to high-fashion product lines and the high-end product lines designed for younger customers, since counterfeits can help set fashion trends and diffuse authentic innovation. This further promotes the product-innovation cycle.

\section{Natural Experiment}

The ideal experiment to test the sales impact of counterfeits would randomly assign a set of brands for infringement by counterfeiters and keep the others immune from counterfeiting. Counterfeit entry, however, is unlikely to be exogenous in practice because entry is more likely to occur for brands with larger sales or a less strict trademark management team. Although the fixed effects in panel econometric models capture unobserved time-invariant firm and product-line characteristics, they do not absorb unobserved time-variant characteristics, resulting in a correlation between counterfeit entry and the error term. Thus, a simple OLS would result in biased effect estimates. To account for endogeneity concerns, I locate appropriate instruments to identify the effects of the counterfeit-entry variable. While I explain the IV strategy in the Appendix, I outline the necessary institutional details here for completeness.

The Chinese shoe industry provides a convenient laboratory for studying counterfeit effects 
because of an unexpected enforcement change around 1995. The policy shift was motivated by shocks external to the shoe sector, specifically an outburst of accidents in the food, drug, agriculture, cotton, and gas sectors due to sub-quality products. The Chinese General Administration of Quality Supervision, Inspection, and Quarantine (AQSIQ, previously called the Quality and Technology Supervision Bureau, or QTSB) issued two notifications to concentrate resources on enhancing quality quarantine and combating counterfeits in the main sectors prone to hazardous materials. However, this left loopholes in the fashion industry for massive counterfeiting. For instance, the AQSIQ devoted approximately $10-12 \%$ of its resources to monitoring footwear products in the early 1990 s, and only $2 \%$ after 1995 (AQSIQ Yearbooks). Data show that shoe brands experienced significant waves of counterfeit entry after the policy shift. The peak in entries came as early as 1996 .

The authentic producers were caught by surprise by the influx of counterfeits. The victimized brands quickly organized internal "brand-protection offices" to compensate for the loosened government monitoring. These internal offices were placed in charge of activities that included identifying counterfeits of their own brands in the marketplace, reporting to the AQSIQ, and collaborating with that organization to trace and outlaw fake enterprises. This is where the relationship between a branded company and the AQSIQ has played an important role. I use the number of workdays between a brand's ISO certification and application dates nationwide as the most suitable proxy. In addition, I match the education and experience backgrounds of the brand and product-line managers with those of the AQSIQ officials based on their biographies to generate alternative IVs. The results are robust.

There were two waves of ISO standards with which the sampled companies had to comply. The first wave was established in 1994 and the other in 2000. For each wave of ISO standards, I collect each company's first-application and final-grant dates for the corresponding certificate and calculate the number of workdays between these two dates (henceforth called "elapsed days"). I then construct a variable that equals the elapsed days for the ISO-1994 certificate for the years 1993-2000 and a variable that equals the ISO-2000 elapsed days from 2001 onwards. I code and match the biographies based on a detailed codebook created by a political scientist and me (Qian and Shih 2011), posted as an online Appendix. I then reverse-code the experience-match variable so that larger values correspond to a worse relationship, keeping the same direction as the ISO proxy.

The ISO-processing days are largely driven by relationships instead of brand or product characteristics. In particular, I confirm this by correlating the ISO variable with the experience-match variables to show that the ISO certification time highly correlates with the preexisting relationship between the managers and QTSB officials because of their overlapping schooling and work experiences (correlation coefficients are 0.79 with the brand-level experience-match variable and 0.63 with 
the product-line-level experience-match variable). When tabulating bivariate correlations between this relationship proxy and the key brand attributes (e.g., size, sales, product quality, or production costs) in my data, I find the largest one to be only 0.08. Similarly, the experience-match variables do not correlate with the company characteristics significantly. ISO and experience-matches are therefore unlikely to affect sales through mechanisms other than their effects on counterfeit entry. ${ }^{3}$

Table 1 shows that a greater number of days spent by a branded company undergoing ISO application correlates positively with the average quantity of counterfeits of that company's brand after 1995. This correlation remains significant in company- and year-fixed-effects regressions. Section 4.1 reports the first-stage results to support IV validity. In robustness checks, I adopt alternative relationship proxies and find qualitatively similar results. Appendix B further documents these alternative relationship proxies.

Insert Table 1 about here

\section{DATA}

\subsection{Data Collection and Description}

My research design requires obtaining data on each brand's product sales, as well as information on counterfeit infringements. Due to the underground nature of counterfeits, I have gathered data through both secondary databases and primary research. The Chinese Industrial Census (CIC) conducted by the National Bureau of Statistics includes detailed financial data and basic firm characteristics (e.g., size, year of incorporation) for the entire population of Chinese manufacturing firms with sales in excess of five million yuan (roughly US\$600,000) for each of the census years. Several waves of data are available for the years 1995 and 1998-2005. While the CIC lists the company's main products, it has no further product-level details. Systematic data on counterfeits are not found in existing sources. Thus it is necessary to conduct primary research to acquire brands' financial statements and counterfeit confiscations.

I gather additional detailed information on sale quantities, transaction prices, and unit production costs at each quality tier for each general type of product, and on the corresponding counterfeits for each of the 31 branded companies in my stratified random sample. I extract the data from the brands' year-end financial statements and other internal records. I specifically have requested brands'

\footnotetext{
${ }^{3}$ The footwear sector has been privatized in China. All of the sampled companies are private, and sales are of market-equilibrium quantity.
} 
databases. ${ }^{4}$ The company data corroborate those in the CIC for the shared variables and years. For instance, the sales, sales costs, profits, and export aggregates of my sample mirror the trends in the census of shoe companies (Table A1). My sample's price data also reflect the same shoe-price trends in the eBay dataset collected by researchers at the University of Chicago (Li et al. 2011). ${ }^{5}$ While the eBay shoe-price data provide useful validation, I used the original company price records in the main analyses. Appendix B details all data diagnostics and sampling methods.

I next obtain the detailed sales quantity, price, and cost data for a more detailed categorization of products than in Qian (2008). For instance, if a company produces six types of products, including high-leg, medium-leg, and regular leather shoes for both women and men, and if there are three quality/cost levels within each type, then I disaggregate data on sales into each of the 18 quality-type combinations. The data thus approach a product-level panel. The input and production costs for the products within each quality-type combination are very similar, although there are variations in color and style (e.g., a decorative button on the side or front) that the current data cannot fully capture. The life cycle of each style is one to two years; however, the product lines remain active over the sampled years. That is, the machinery and organization of each product line do not change for any existing quality tier.

Brands offer a range of products, and each brand classifies its products into three quality tiers when reporting to the government. The low-tier product lines produce shoes with prices averaging around 17 USD $(\mathrm{SD}=8)$, the medium-tier lines produce shoes averaging $27 \mathrm{USD}(\mathrm{SD}=10)$, and the high-tier lines offer an average price of 43 USD $(S D=19)$. New product lines added in later years are also clearly captured in the data; I analyze them separately from existing product lines. Such fine-level aggregations are appropriate for the analyses at hand, since I am interested specifically in the differential sales impacts by quality-tier level. As detailed in Section 4.4, I conduct additional cluster analyses where I form natural clusters of quality tiers based on the unit production costs in the full sample of existing product lines across brands.

I collect data on the year that counterfeits entered the market for each quality tier of each brand, whenever that existed, from each authentic firm's brand-protection offices. Because these offices and the AQSIQ work together to combat counterfeits, the AQSIQ has offered feedback to each brand, including statistics on its confiscated counterfeits. I therefore obtain records of the counterfeits

\footnotetext{
${ }^{4}$ The company contacts were very responsible, and they were cautious about not providing casual estimates in interviews. Instead, they emailed or faxed me after checking with their sources.

${ }^{5}$ The researchers collect transaction-level data on eBay for several product categories. For each transaction, the data include the shoe brand and type, final transaction price, shipping cost, seller and buyer IDs, product condition, starting bid, and number of bids.
} 
that the brands discovered and reported to the government, as well as the counterfeits from the market and manufacturing sources raided by the AQSIQ. The AQSIQ also has kindly provided me with some of the internal financial records on the counterfeit entities and statistics on the characteristics of the counterfeit shoes confiscated. Data show that counterfeiters usually imitate all quality levels of authentic products of a given brand, even though they use similarly inferior materials (e.g., synthetic leather or rubber) to produce shoes that mimic the different appearances of these products. Counterfeiters' prices can be as low as a quarter of the authentic product price.

Table 1 provides descriptive statistics for the 31 companies over the 12-year panel. The branded companies report that their records represent the majority of their counterfeits. "There were probably other [counterfeits]," a representative of a brand comments, "but we did not feel threatened by them, so we didn't care too much to track them down." I creat an indicator variable for noticeable counterfeiting equal to 1 if a branded product of a particular quality tier had been infringed upon, and zero otherwise. I probe into the impacts of an unexpected, massive presence of counterfeiters on the sales of each quality tier within an authentic brand. I thus analyze different quality tiers separately, so that brand-level and quality-tier-level variations upon counterfeit entry are more relevant than minor variations at the product level within a brand.

To control for the overarching macro-environment and consumption patterns, I obtained data on a common set of macro-indicators: GDP growth, GDP per capita PPP, the Consumer Price Index (CPI) from the World Development Indicator (WDI) database, and the economic inequality measures (Gini coefficients) from the UN Human Development Reports. All these data are available at annual levels in the sample period.

\subsection{Descriptive Evidence: Sales Shares Shift to High Tiers}

Table 2 tabulates the summary statistics of the analyzed variables before and after 1995, the newpolicy year. As Table 2 shows, AQSIQ on average spent $11 \%$ of total resources in monitoring the shoe sector pre-1995, and only $2 \%$ afterward. This drop was accompanied by an influx of counterfeiting. While the median quantity of counterfeits across brands was zero before 1995, counterfeits surged to 857,100 pairs per year, on average, in the sampled years after 1995. The product costs and prices of counterfeits were on average only a fraction of those of authentic products.

Insert Table 2 about here

Figure 1a plots the sales of shoes at the three broad quality tiers, as classified by the companies, as percentages of total domestic sales. It is interesting to note that the quality lines moved upward 
after entry by counterfeiters. That is, the higher-end shoes occupied larger shares in total sales post entry, and the low-end shoes saw their shares decline dramatically. While I will present more rigorous analyses in the next sections, these summary statistics paint a general picture of the differential effects of counterfeit entry on sales of authentic products at different quality levels.

Part of the increase in sales was due to the introduction of new products. I therefore separately compile the sales shares for products of fixed quality pre- and post-entry by counterfeiters and those for the new products introduced after the infringements (See Figure 1b). Among the fixed quality tiers, the percentage of sales of high-end shoes increased post-entry, but those of medium-quality and low-end shoes declined. However, the decline in sales of medium-quality shoes tended to be overcompensated for by the sales of new products in the same quality tier, whereas the sales of new products in the low-end tier were not sufficient to make up for the category percentage drop.

Insert Figures 1a and 1b about here

\subsection{OLS}

The increases in the sales share of high-end products as shown in Figure 1 could be due in part to the spillover effects of counterfeiting and also be a direct consequence of new-product introduction after entry. To disentangle these two parts, I match products of similar quality tiers before and after entry by counterfeiters throughout the sample period, based on their similar price and costs. I compile this sample of existing product lines separately from the rest of the sample of new product lines. I then investigate entry effects on the sales of these existing product lines according to three quality tiers: low, medium, and high. I analyze both sales quantity and sales value but use the former in the main specifications. As Gosline (2009) shows, based on a U.S. sample, that some people are willing to pay twice as much for an item when they think they can use it to send cues about wealth and taste (likely the case for high-end products), sales quantity is the most appropriate measure that does not conflate with price differences.

$$
\begin{aligned}
\ln \left(\text { Sales }_{a j t}\right) & =\beta_{0}+\beta_{1}^{T} \text { Entry }_{a j t} * \text { Tier }_{a j t}+\beta_{2} \ln P_{a j t}+\beta_{3}^{T} \operatorname{TierDum}_{a j}+\beta_{4}^{T} \text { BrandDum }_{a} \\
& +\beta_{5}^{T} X_{a j t}+\beta_{6}^{T} \text { YearDum }_{t}+\beta_{7}^{T} \operatorname{ProdDum}_{a j}+\beta_{8}^{T} \text { YearDum }_{t} \operatorname{TierDum}_{a j}+\epsilon_{a j t}
\end{aligned}
$$

where Entry ajt $_{\text {is }}$ an indicator variable that takes on a value of 1 if there is a positive presence of counterfeits in the market for brand $a$ 's product type $j$ in year $t$. $\operatorname{Tier}_{a j t}$ is a vector of dummies indicating the three levels of quality. With this parametrization, $\beta_{1}$ is a vector of parameters denoting the tier-specific entry effects. $\ln P_{a j t}$ is the log price of the product, and $X_{a j t}$ is a vector of control characteristics, such as company $a$ 's age and size and product $j$ 's shoe orientation (male or female) 
or usage (winter boots, sandals, dress shoes, etc.) in year $t$. The fixed effects for the panel year (12 years) and product lines within the quality tier of the 31 brands control for year-specific factors and time-invariant product-line characteristics.

A simple OLS regression shows that counterfeit entry has a very significant correlation with authentic sales, implying that after entry, authentic sales went up by $35 \%$. This effect is partly an artifact of the endogeneous counterfeiting treatment. The omitted variable bias potentially enters OLS in two directions: an upward bias because brands with larger sales are more likely to experience counterfeiting, and a downward bias due to internal management effects, which are positively correlated with the sales outcome but negatively correlated with the entry of counterfeits. In particular, a brand with good internal management may ward off counterfeits effectively and maintain high sales. In fact, when simply regressing log sales quantities on the fake entry dummy and a year trend, the entry coefficient is very large. While the company-fixed effects help control for the omitted brand effects, they do not control for the time-variant management effects, resulting in a downward bias in the OLS estimates. I therefore adopt a new IV to address this endogeneity concern in Section 4.

\subsection{Institutional Data to Preclude Alternative Explanations}

The econometric model presented in the next section formally addresses the endogeneity concerns. As explained in Section 2.1, confounding factors will not lead to bias in the treatment-effect estimate as long as they are orthogonal to the treatment variable. The natural experiment and the instrumentalvariable approach therefore would identify the effects of entry by counterfeiters. Nonetheless, for the interested reader, I discuss several more institutional details here to preclude alternative explanations before moving on to the formal models.

China entered an incredible economic boom in the late 1980s, which continued through the 1990s. Easy credit conditions prevailed there primarily in the 1980s (Naughton 2002). An unsustainable credit expansion drove demand well beyond supply, and prices began to rise rapidly. At the peak, the CPI was growing at around $25 \%$ per year, and China was taking in a massive quantity of imports, running a substantial current-account deficit. China had to tighten credit conditions in the early 1990s, in the hope of slowing the acceleration of non-performing loans (Gabriel 1998). The prime minister Zhu Rongji took strong steps to slow down the growth. Investments and growth dropped sharply, as did the rate of price increases. By the late 1990s, China experienced deflation. Given the negative macroeconomic trends in the mid- to late-1990s, the positive coefficients on instrumented counterfeit entry (controlling for year and company dummies), as reported in Section 3, provide rather convincing evidence that the higher sales of authentic products were due to counterfeits rather than macroeco- 
nomic factors.

The regional-level macroeconomic environment data reveal a drastic increase in inequality in the late 1980s and early 1990s, instead of the late 1990s, when spikes in the high-end authentic sales were most pronounced. Thus, the increases in high-end shoe sales are not likely to be attributable to inequality. I also gathered data on CPI specifically for the shoes and garments sector from the Yearbooks, and find this price index to follow the overall CPI quite closely (correlation coefficient $=$ 0.89). I control for all these macroeconomic variables in my analyses. The sales increase is also not an artifact of inflation.

Chinese laws granted import licenses only to registered companies. The counterfeiters had no access to advanced shoe-making technology, which was primarily imported from Italy. It is possible that China's accession to the WTO broadened technology imports, which in turn enabled high-quality counterfeits. Yet this aftermath of the WTO was not until the mid-to-late 2000s (Cogitamus Consulting 2009), which is at the tail end of the time period I examine. The jumps in my brand-related sales data took place immediately upon entry by the counterfeiters of the brands. Nonetheless, I control for this timeline in regressions, and the results are robust. I perform additional institutional research and data analyses to rule out confounding factors. I detail them in Appendix B, along with other robustness checks.

\section{EMPIRICAL IDENTIFICATIONS}

A richer database at the product-line level, as compared to that of my earlier study with firmlevel data, yields greater identification power at the product-quality level. Specifically, each brand has several quality levels, with different sales quantities and values of products at each level. Therefore, the loosening of Chinese government enforcement for footwear essentially created dozens of "miniexperiments," which I exploit to identify the entry effects of counterfeiters on authentic product sales.

\subsection{First Stage IV Estimations}

I instrument for the entry of counterfeiters using the plausibly exogenous enforcement shift away from the footwear industry and its interactions with the relationship between each brand and the AQSIQ. I construct an indicator variable, Loose, to benchmark the years with loosened public enforcement for shoes (Loose $=0$ before 1995 and 1 since 1995). This enforcement diversion and its interaction 
with the relationship between a brand and the AQSIQ served as the main instrumental variables for counterfeit entry. Because the enforcement diversion arose from a series of accidents in other industries, it is plausibly exogenous to the shoe sector. This IV also satisfies the exclusion restriction, because tightened public enforcement in other sectors is not supposed to affect shoe sales directly. Because the number of workdays it took each brand to obtain ISO certification from the AQSIQ (averaged across its subsidiaries in various regions) proxies for the brand's acquaintance only with the AQSIQ, this ISO proxy does not affect sales directly.

I identify the entry by counterfeiters with the equation below:

$$
\begin{aligned}
\text { Entry }_{a j t}= & \alpha_{0}+\alpha_{1}(\text { Relation*Loose })_{a t}+\alpha_{2} \text { Loose }_{t}+\alpha_{3} \text { Relation }_{a t}+\alpha_{4} \text { BioMatch }_{a j t} \\
& +\alpha_{5}(\text { Biomatch*Loose })_{a j t}+\alpha_{6}^{T} \text { YearDum }_{t}+\alpha_{7}^{T} \text { BrandDum }_{a}+\psi_{a j t}
\end{aligned}
$$

where Entry ${ }_{a j t}$ is an indicator variable for the existence of counterfeits of brand $a$ 's product type $j$ in the market at time $t$, and it equals 1 if there are counterfeit infringements for brand $a$ in year $t$. Relation $a t$ is the ISO time proxying for the relationship between brand $a$ and the AQSIQ, and (Relation*Loose) $a t$ is the interaction variable between this ISO proxy and the legislation dummy. BioMatch ${ }_{a j t}$ is the variable based on matching the education and experience background of the manager of brand $a$ 's product-line $j$ and that of the AQSIQ officials, and (Biomatch*Loose) ${ }_{a j t}$ is its interaction variable with the policy shift dummy.

I bring in additional product-line-level exogenous variations in relationships by compiling the product managers' experience matches with AQSIQ officials. With an additional level of random variation due to this alternative IV, the rationale for the added effort is to increase the amount of random variation in counterfeit sales and thus increase the efficiency of the IV estimation. About a third of the bios could not be found or matched, creating a missing-data problem. I therefore use the nonparametric approach of Qian and Xie (2011) to impute these unobserved missing values. An important assumption in a missing-data approach is the missing-at-random (MAR) assumption, which requires the "missingness" to be independent of unobserved values, given other observables. Even though this is a plausible assumption when a rich set of observables (e.g., observables at the firm level, counterfeit sales, cost, price) is conditioned on, it is typically untestable. I therefore report this analysis as a robustness check and use the brand-level relationship for the main specifications. Combating counterfeits primarily involves brand-level collaboration with the AQSIQ, so the brandlevel relationship is the most relevant in any case.

In addition to the potential endogeneity of the entry variable, product price may be endogenous to sales. In robustness analyses, I adopt the traditional IV of product cost for that, and the results on 
counterfeiting effects remain qualitatively unchanged (Tables A2-A6). The model is as follows:

$$
\ln P_{a j t}=\gamma_{0}+\gamma_{1} * \ln C_{a j t}+\zeta_{a j t}
$$

where $\ln P_{a j t}$ denotes the $\log$ price of brand $a$ 's product $j$ at the year $t$, and $\ln C_{a j t}$ similarly denotes the corresponding product cost in logs.

Table 3 displays the estimates from alternative first-stage specifications. As shown in Columns 1 and 2, the loose-policy indicator and the interaction IV predict counterfeit entry, statistically significant at the $1 \%$ level. These robust estimation results across alternative specifications tell a clear and consistent story: the public enforcement diversion encouraged counterfeit entry (positive and significant coefficient on "Loose"), and that encouragement was stronger for counterfeiters of brands that had a worse relationship with the AQSIQ than for those of other brands (positive and significant coefficient on "Relation*Loose," using two alternative proxies for relationship). Column 3 illustrates the relevance of the experience-match variable and counterfeiter entry. Column 4 shows a specification where I employ all instruments with year- and brand-fixed effects, as I also do in the estimations underlying the results in Column 5 of Table 5.

Insert Table 3 about here

\subsection{Regressions for Sales of Fixed Quality Levels}

To test the counterfeiting effect on the branded product sales of the three existing quality tiers (low, medium, and high), I simultaneously estimate equations (1) in Section 3.3 and (2) in Section 4.1. Using the log sales quantity and values as alternative dependent variables, I arrive at robust results. For brevity, I report the specifications with the log sale quantity as dependent variables and detail the others in the online Appendix. Table 4 presents the results and reveals interesting patterns. Results show that the entry of counterfeiters has a positive effect on high-end shoe sales but a negative one on low-end sales, statistically significant at the $5 \%$ level (Column 2 in Table 4 ). The magnitudes of the entry coefficients are larger than the OLS estimates, as discussed in Section 3.3 (coefficient $=0.49$ for the high-end sales and -0.75 for the low-end sales), implying that counterfeiter entry increased highend authentic sales by $63.23 \%$ and decreased low-end sales by $52.76 \%$. I also execute the IV regression within each quality-tier stratum of shoes separately. The results are robust (Columns 3-5 in Table 4).

Counterfeit entry hurts low-end products but helps high-end ones within a brand. This is because counterfeits are closer substitutes for low-end shoes than for high-end ones. Counterfeiters entered for different quality tiers for each infringed brand, yet it is harder and more costly to imitate the high-tier products due to both technology and incentive constraints. It is intuitive that the low- 
end product lines suffered more business-stealing effects due to counterfeits. The sales of the high-end authentic products increased significantly after counterfeiters entered, controlling for year- and productline fixed effects and other time-varying company and shoe characteristics, such as company age and size. This reflects the potential advertising effect of counterfeits on the brand. Counterfeits could serve as a form of mass advertising, increasing brand awareness, especially for customers who would not have been captured by the brand otherwise. Qian and Xie (2013) provide survey results in which Chinese consumers learned about their favorite brands initially through counterfeits. ${ }^{6}$ In China, brand awareness has definitely been an increasing function of the number of people using the brand.

This relates to the "diseconomies of scope" theory proposed by Bresnahan et al. (2010) and to the finding in Godes and Mayzlin (2009) that the word of mouth that is most effective at driving sales is created by less loyal customers. Counterfeits could in that sense serve as "buzz agents" by providing "independent" affirmations of the brand. The advertising effect is more pronounced when new customers who learn the brand name, and who value quality and authenticity, subsequently choose the high-end authentic products. These new customers recruited by the counterfeits are then acquired by the authentic company. Thus the potential spillover effect of counterfeits may be considered an "externality" to the branded firm. Since the authentic branded companies do not internalize such advertising costs in their own optimizations, the advertising hype can lead to heterogeneous sales impacts for authentic products of different quality tiers. It can both shift and rotate demand functions for products of different quality levels. Notably, because counterfeits impose less competitive pressure on a high-end authentic product due to a wider quality gap, the equilibrium sale quantity of the high-end authentic product primarily increases when counterfeits enter the market and boost brand awareness. The equilibrium sales quantity of the low-end authentic product declines in net as the business-stealing effect of counterfeits outweighs the advertising effect.

Benchmarking against the overall observed change in sales (Figure 1), the point estimate of the entry coefficient in the high-end sales sample (Table A2) implies that $29 \%$ of the increase in the sales of high-quality-tier shoes can be attributed to the net positive spillover effects of counterfeits. ${ }^{7}$ The

\footnotetext{
${ }^{6}$ Since the Cultural Revolution in 1976 and the opening up of the market economy, there has been unleashed energy from both the supply and demand sides. Chinese consumers have been delighted and overwhelmed by the boom in brand and product varieties. The general lack of information about different brands does not match consumers' eagerness to use and associate with brands. Therefore, they often look to others or look for marketplace "trends" to learn about popular brands (Lin 2011).

${ }^{7}$ The coefficients translate to a $63.23 \%$ increase in quantity and a $50 \%$ increase in the value of high-end sales, converting from the log scale. Drawing relevant summary statistics on the sale quantities, prices, and percentages of total sales pre- and post-entry by counterfeiters in Figure 1, the overall observed percentage change in sales is $\frac{558.28 * 32.24 * 17.0 \%-309.38 * 26.21 * 13.9 \%}{309.38 * 26.21 * 13.9 \%}=172 \%$. Similarly, the fraction of change due to the spillover effect of counterfeits is $\frac{50 \%}{172 \%}=29 \%$.
} 
medium-quality authentic products did not witness significant changes in sales due to counterfeiting, although the sign of the coefficient on the instrumented entry variable is negative. However, the sales of the low-end authentic products dipped significantly upon the entry of counterfeits, both in quantity and value. The coefficients on the instrumented entry dummy are -0.75 in the pooled regression (Column 2 of Table 4) for low-end sales quantity and values (Table A2), implying a 53\% drop in sales for the low-end shoes. A similar back-of-the-envelope calculation reveals that $86 \%$ of the decline in low-end sales after counterfeiters' entry comes from the net negative substitution effect. ${ }^{8}$ This is indicative of the moderate advertising and fierce competitive effects of counterfeits; in net, the counterfeiting effect on high-end sales is positive and of moderate magnitude while that on low-end sales is largely negative.

In robustness checks, I repeat the simultaneous equations model estimations by adding a control for the log average price of counterfeits of each quality tier, as instrumented by the log unit production cost of counterfeits. The estimation results do not change qualitatively. That is, the entry coefficients remain positive and significant for the high-end sales quantity and values, and negative and significant for the low-end sales quantity and values. Because the data for counterfeit prices are less systematic, I keep my main specifications as described earlier. I also conduct robustness analyses with controls for the time-variant brand-advertising expenditure and the number of company stores of the brand in alternative specifications. The results are qualitatively similar. Qian (2008) shows that the authentic brands' advertising expenditure did not change significantly after entry by counterfeits, so this control is not collinear with the main treatment variable. I control for advertisement (Tables 4-6). However, because the number of stores is endogenous to sales and counterfeiter entry, I do not include it in the main regression specifications. To the extent that the IV teases out the plausibly exogenous parts of counterfeit entry, the sales responses are less susceptible to omitted variable bias, especially in the time period immediately following entry.

Insert Table 4 about here

\subsection{Robustness Analyses}

In addition to the manufacturer's own classifications of the three quality levels, I conduct a cluster analysis of all the fixed-quality (from existing product lines) shoe products in the sample based on the unit production costs of the products. Notably, it is not meaningful to examine the distribution of raw unit cost across different quality tiers because the cost is also related to the product type and therefore it is not of value to compare the cost across product lines from different quality tiers. As for

\footnotetext{
${ }^{8}$ The overall percentage drop in low-end sales is $\frac{309.38 * 26.21 * 32.1 \%-558.28 * 32.24 * 5.6 \%}{309.38 * 26.21 * 32.1 \%}=-61 \%$, of which the counterfeiting effect accounts for $\frac{-53 \%}{-61 \%}=86 \%$.
} 
the other analyses in this study, the product lines (types) need to be controlled for in this comparison. I therefore regress the deflated unit production cost on the product line dummies and obtain the regression residuals. Boxplots of the cost residuals of the three quality tiers show that the manufacturers' classifications of quality tiers are rather clear, in that the majority of sampled data across quality tiers do not overlap across the three quality tiers (Figure 2a). In particular, the high-end and low-end shoe distributions include completely distinct unit production costs because the minimum line of the high-end distribution is above the maximum line of the low-end distribution.

Insert Figure 2 about here

I then apply standard cluster analysis using the K-means method on the unit production cost residuals. This procedure forms three natural clusters. Figure $2 \mathrm{~b}$ plots the distributions of quality (proxied by the unit production cost residuals) of the three quality clusters. It appears that the three clusters are further separated from each other as compared to those defined by the manufacturers. I then repeat the simultaneous equation estimations on these three natural clusters instead of the three tiers based on manufacturers' classifications (Column 1 of Table 5). I also repeat the IV regressions on the three clusters separately (Columns 2-4 of Table 5) and report the formal regression results on these sets of products in Table 5. Results are again consistent and robust: the entry effect for the sale quantity of the cluster of high-quality shoes remains positive and significant, implying a $51 \%$ increase in sale quantity. However, I estimate the effect to be negative for the cluster with the lowest quality shoes, statistically significant at the $1 \%$ level. The coefficient magnitudes become larger because the natural clustering results in more distinct quality tiers, hence revealing the net positive effects on high-end sales and negative effects on low-end sales as more salient.

As a final robustness check with these naturally clustered data based on costs, I estimated Equations (1)-(2) with additional interaction variables between the year trend and each of the brand dummies. This allows for a different time trend for each brand in the sample. Results are qualitatively unchanged. I also employ the full set of IVs, as listed in Column 4 of Table 3, including the main ISO relationship proxy and the variable based on experience-matches between the product-line managers and the AQSIQ officials. Results are again robust (Column 5 of Table 5 ).

I then perform alternative clustering based on the unit production price instead of cost, repeating the same steps as described in the cost case. The results are qualitatively similar (Column 6 of Table 5). However, price may be an inferior proxy for quality because pricing can be based partly on brand premium, which has little to do with the actual quality that went into producing a particular pair of shoes.

The IVs provide exogenous identification of the counterfeiting effects such that the effect es- 
timates do not suffer from omitted variable bias due to confounding trends. In addition, the panel structure and the presence of the control group of brands that were never infringed upon by counterfeits serve as solid benchmarks for comparison, which helps net out the macroeconomic trends. I further conduct robustness analyses, including the interaction variables between the year trend and brand- and tier-fixed effects. The results are again robust with this model, which thoroughly controls for potential confounding trends that may be heterogeneous to different brands and quality tiers.

Insert Table 5 about here

\subsection{Effects of Counterfeits on Product-Level Sales Over Time}

While Section 4.2 tests the overall impacts of counterfeit entry, this section attempts to trace the sales effects over a longer time horizon. For the samples of shoes at each quality tier, I regress the log sales quantity on the set of dummies indicating different years relative to counterfeiter entry, controlling for the time-varying company attributes, macro conditions, and company-fixed effects.

$$
\begin{aligned}
\ln \left(\text { Sales }_{a j t}\right)= & \beta_{0}+\sum_{k=-5}^{5} \beta_{1 k} * \text { YearToEntry }_{a, j, k}+\beta_{2} * \ln \hat{P}_{a j t} \\
& +\beta_{3}^{T} * X_{a j t}+\beta_{4}^{T} * \text { YearDum }_{t}+\beta_{5}^{T} * \operatorname{ProdDum}_{a j}+\beta_{6}^{T} \operatorname{BrandDum}_{a j}+\epsilon_{a j t}
\end{aligned}
$$

where I regress the $\log$ sales quantity of brand $a$, product $j$ in year $t$ on the set of dummies indicating years $(k)$ relative to entry from five years pre-entry to five years post-entry, controlling for the instrumented log product price and other characteristics. I plot the regression coefficients on the year indicators against the corresponding years relative to entry for the sample of existing product lines and the sample of new product lines in Figures 3 and 4, respectively. Because the new products were introduced only after facing competition from counterfeiting, the coefficients for the years prior to the infringements were not plotted in Figure 4.

Figure 3 demonstrates the positive effects of counterfeits on high-end shoes. This advertising effect was felt immediately upon the entry of counterfeits and lasted for several years before it dwindled. It is possible that counterfeits first served to improve consumer awarenesses of the brand and later contributed negatively to brand equity because some consumers misattributed the inferior counterfeit quality to the brand itself. The negative impacts on the other two quality tiers are quite large and long-lasting. Some of the dips in these sales are offset by the sales of new products in these two tiers, as indicated in Figure 4. The regression underlying Figure 3 uses the year of entry by counterfeits as the benchmark, so all the coefficients plotted indicate the relative change in the log sales quantity of a particular quality tier in the respective year relative to entry. Because almost all the new products were introduced at least a year after the counterfeits entered the market, Figure 4 uses the first year 
of observation, or one year after entry, as the benchmark for comparison. These two figures are most suitable for demonstrating the changes in the log sales quantity in the years relative to entry within each quality tier.

The trend that the positive effect on the high-end shoes was largest in the year immediately following the massive entry of counterfeits again rules out the alternative explanation that the authentic companies' own self-enforcement was the driving force. These firms invested in self-enforcement with some lags, and the number of company stores grew in the later years of the sample period, which is the opposite of the trend for high-end sales increases.

Insert Figures 3 and 4 about here

\subsection{Mechanisms of the Spillover Effect of Counterfeits}

While the negative effect of entry by counterfeiters on the sales of low-end shoes is consistent with traditional intuitions about business-stealing, the positive effect on the sales of high-end shoes is at first surprising. Yet positive effects of IPR infringement have been termed the "piracy paradox" by Raustiala and Sprigman (2009), who study historical incidences of fashion innovation and find that imitation could turn a formerly innovative design into a nonexclusive feature and stimulate further product differentiation.

A strand of literature proposes that copyists create barriers to entry for competitors (Givon and Muller 1995) and help the originator establish its technology as an industry standard, with switching costs further cementing the originator's competitive position (Katz and Shapiro 1994). Unlike software and other high-tech industries, there is very little standard-claiming behavior in the Chinese shoe sector. In addition, the shoe industry's size has been stable since the late 1980s, and national statistics show that the number of employees in the footwear and garment industry was approximately 1,750,000 throughout the 1990s (Tables 12-2 and 13-2 in each YearBook, Chinese National Bureau of Statistics). According to the Basic Unit Census of China (National Bureau of Statistics 1996), most legal shoe companies were established in the late 1980s. This evidence suggests that the positive spillover effect of counterfeits is not likely to work through the entry-barriers argument in this context.

In this subsection, I present a set of analyses that demonstrate the potential advertising effect of counterfeiting due mainly to increased brand awareness. Specifically, I implement a difference-in- 
difference-in-difference model with simultaneous equation estimations:

$$
\begin{aligned}
\ln \left(\text { Sales }_{a j t}\right)= & \beta_{0}+\beta_{1}^{T} \text { Entry }_{a j t} * M_{a j t} * \operatorname{Tier}_{a j t}+\beta_{2}^{T} \text { Entry }_{a j t} * \operatorname{Tier}_{a j t} \\
& +\beta_{3} M_{a j t} * \operatorname{Tier}_{a j t}+\beta_{4}^{T} X_{a j t}+\beta_{5} \ln P_{a j t} \\
& +\beta_{6}^{T} \operatorname{TierDum}_{a j}+\beta_{7}^{T} \text { YearDum }_{t}+\beta_{8}^{T} \operatorname{ProdDum}_{a j}+\beta_{9}^{T} \text { BrandDum }_{a j}+\epsilon_{a j t}
\end{aligned}
$$

where $M_{a j t}$ is a set of moderating factors as detailed in the following paragraphs, $M_{a j t}=\{$ High fashion, non-renowned, single-brand, non-famous, young brand, young cohort\}. I define all the other variables as before. The model is equivalent to one that includes the first-order terms of $M_{a j t}$, one at a time, as well as the two-way and three-way interactions with the entry dummy and the set of dummies on quality tiers. A benefit of the current model setup is that it is easily interpretable: $\beta_{1}, \beta_{2}$, and $\beta_{3}$ all correspond to the tier-specific effects. I again implement IVs to address the endogeneity concerns, and compile the results in Table 6.

The first piece of evidence in the data that points to the advertising effect is that the positive sales impact of counterfeits is most pronounced in the product lines for dress shoes and women's highleg boots (henceforth "high fashion"). This is expected because people buy these products not just out of necessity but to keep up with the latest style. Column 1 of Table 6 reports the IV regression results on the log sales quantities of the three quality tiers of these fashion boots, and the entry effects on the high-end fashion boots are estimated to be as high as $0.76(0.37+0.39$ in Column 1 of Table 6$)$ for the $\log$ sales quantities, statistically significant at the $1 \%$ level. The demand-enlarging effects for the less fashionable products are much more moderate (coefficients are estimated to be 0.39 in Column 1). Further, I conduct the IV regression on the stratified sample of "high fashion" shoes and the rest of the sample separately, with log sale quantities and values as alternative outcomes, respectively. I display the complete tabulations of the coefficients in these estimations in Tables A3-A4, and again the results are robust.

Insert Table 6 about here

The second piece of evidence that speaks to the advertising effect is that the sales impact of counterfeits is more positive for the high-end shoes of brands that were less famous at the time of infringement. The Chinese Trademark Office grants the "well-known (renowned) brands" designation to national and international brands according to the Chinese Trademark Law and the Paris Convention. ${ }^{9}$ I repeat the IV regression estimations for the three tiers of shoes, testing the moderation effect of the variable "non-renowned" which indicates the set of brands not listed as "renowned" at the time of in-

\footnotetext{
${ }^{9}$ The modern concept of the "renowned" trademark is codified in Article 6bis of the International Convention for the Protection of Intellectual Property (the Paris Convention). It uses the French expression "notoirement connue," literally "notoriously known", or in better English, "well known."
} 
fringement by counterfeits. As shown in Column 2 of Table 6, the average effect of counterfeiting on the sales quantities of high-end shoes of renowned brands is 0.23 , and on that of the non-renowned brands is $0.69(0.23+0.46)$, statistically significant at the $5 \%$ level. The positive effects on the non-renowned brands are apparently much higher than the corresponding effect sizes for the renowned brands. For these non-famous brands, the entry effect on medium-tiered shoe sales is also positive. While the effect on low-tiered shoes is still negative and statistically significant, the point estimates are less negative than those in the renowned-brands sample. Results are again robust when executing the regressions separately for the samples of renowned and non-renowned brands. The demand-enlarging effects for the renowned brands are much smaller, with $12 \%$ of the increase in sales for the high-tiered shoes attributable to the spillover effects (Table A6). The effect on the low-tiered shoes is again significantly negative.

Along the same line of thought, I use three other indicators for how established the brands are and stratify accordingly. First, I stratify based on whether the brand was authenticated as "Famous Brands in China" at the time of infringement. The positive effect is again larger for the brands that were not "famous" at the time of infringement by 0.33 , as compared to the domestically famous ones (Column 3 of Table 6).

Second, I stratify by the age of the brands. If counterfeits serve as mass advertisement, then infringement surely has a larger impact when information about the brand has not yet been widely disseminated. This suggests that the positive effects of counterfeiting is larger for newer brands than for more established brands. Such is the case empirically (Column 4 of Table 6). I define "new brands" as those whose age is below the median level. It is interesting to note that the impacts on the low-end authentic sales are highly negative here, demonstrating the severe double-edged effects of counterfeiting. While spreading the word is especially helpful for a new brand's high-end products, low-end sales are hurt significantly because counterfeits serve as such close substitutes for unknown brands without a loyal customer base.

In addition, I stratify based on the number of sub-brands the branded company owns. Results again show that the positive effect is larger for brands that only have a single brand compared with more established brands with multiple sub-brands (Column 5 of Table 6). The net positive effect for the high-end shoes is $31 \%$ higher for the brands with just a single brand than for those with multiple sub-brands, based on the coefficients $(0.48+0.27$ vs. 0.27$)$.

Finally, I stratify by the types of shoes tailored to customers of different age groups. Although the classification may not be perfect because some shoes can be purchased across age groups, I have worked with the companies to classify the shoes carefully based on their design intentions and records 
of customer demographics. For instance, medium-leg men's workboots are primarily worn by customers aged 20-45, and "old man's shoes" (a type of shoe with thick cotton insides) are designed for senior people. I find that the positive spillover effects of counterfeiting are larger for shoes that are made for young people than for those targeting older generations (Column 6 of Table 6 ). If the effect were not due to an advertising mechanism, then I would expect to find the effect to be similar across both the different shoe types and age groups.

In sum, these stratification analyses show that the positive marginal effects of counterfeiter entry on the sales of authentic shoes are largest among high-fashion boots and high-tier shoes of the less established brands. The effects are also larger for shoes made for young people than for those aimed at the older generation. These are exactly the products and brands that are expected to benefit most from mass advertising. Counterfeits and imitations help establish "trends," and trends are key drivers of sales (Raustiala and Sprigman 2010). The results, therefore, provide strong evidence for the advertising effects of counterfeits. The positive effect extends beyond the fashion industry. In an interview with the New York Times, Michael Simon, the chief executive of LogMeIn, a company whose software is used in smartphones and tablets, comments, "If people are going to steal something, we sure as hell want them to steal our stuff. When you have a saturated market like Microsoft and have no growth in these devices, then it might be different" (Schmidle 2010).

\subsection{Discussions of Results}

The findings presented so far explain the sales mechanism that could further drive authentic producers' quality upgrades in response to counterfeit infringements. In particular, among the set of branded companies whose products started at similar price and quality levels, only those that experienced counterfeit infringements strove to innovate after being counterfeited extensively. The companies that were better acquainted with the AQSIQ and did not experience massive counterfeiting threats did not demonstrate internal quality upgrades. Counterfeiting effects yield interesting patterns: not only did firms innovate to alleviate competition from counterfeits, but I also find that their percentages of sales concentrated more toward higher-end shoes even for the fixed-quality tiers over time. In hindsight, the findings in this study that counterfeits have positive effects on high-end products and negative substitution effects on low-end products would reinforce authentic firms' incentives to innovate. ${ }^{10}$ Innovation strategies had positive effects for consumers, because the quantity demanded increased, the product

\footnotetext{
${ }^{10}$ The authentic firms were indeed delighted to learn this when I presented the results to them.
} 
variety increased, and the deflated price associated with the basic characteristics remained stable. ${ }^{11}$

It is worth noting that the data at hand are insufficient to further tease out the mechanism of the advertising effect. Berger and Ward (2010) show that consumers of lower-tier luxury brands are qualitatively different than those of higher-tier luxury brands in terms of the expertise necessary to recognize the brand and to consume. In the current dataset, there is no significant correlation between quality tier and likelihood of being counterfeited. However, as I acknowledge earlier, the annual-level data do not capture differences in counterfeit entry across quality tiers at finer time intervals. Further, it could be that low-tier consumers do not need much advertising to purchase, while counterfeits serve to educate consumers in the higher tier. It is difficult to ascertain these dynamics of product expertise with the present data, and they are interesting directions to pursue for future research. Future research could also study the impacts of counterfeiting on fashion cycles. A qualitative study showed that Shanghai Tang, a famous Chinese apparel brand, rolls out brand new collections every six months to address the risks of copycats (KMPG 2010).

One other limitation in the data is that only confiscated counterfeits are recorded and reported. As discussed in the data section, this motivates my use of the dummy variable indicating significant jumps in counterfeiting in the main specifications, though using the amount of counterfeits generates qualitatively similar results. Suppose that the brands internalized the anticipated counterfeiting effects in their self-enforcement investments (i.e., they tracked down more of the counterfeits for the low-end quality tiers and fewer for the high-end ones); this would imply that the effect sizes as reported in the paper may be overestimated while the direction is the same. Similarly, should the firm's priors on the counterfeiting effects be the opposite when they decided to invest in self-enforcement, the existing effect estimates would be conservative estimates of the actual heterogeneous effects. In my interviews with brand managers, I find no evidence that they were aware of such heterogeneous effects, and in fact they were surprised to learn the findings afterwards. They also claimed that they had tracked down most of their counterfeits.

\section{CONCLUSION}

The sales impacts of counterfeits represent an urgent concern for business managers and policy makers alike. The present research uses product-line-level panel data on Chinese shoe companies to investigate the heterogeneous sales impacts of counterfeiting. I identify an exogenous loosening of

\footnotetext{
${ }^{11}$ I also replicate these results in the lab. Lab experiments further enrich the evidence for the advertising mechanism based on respondents' stated preferences and purchase motivations. Please see the online appendix at http://www.nber.org/ yiqian for more details.
} 
public enforcement in monitoring footwear trademarks and its differential consequences in counterfeit infringements for brands with heterogeneous degrees of acquaintance with the government agency handling counterfeit enforcement. I operationalize this difference-in-difference approach by the interaction between enforcement diversion and the relationship proxy to instrument for counterfeiters entry. The empirical results are robust across specifications and consistent with theory. In addition, I establish the causal relationship between counterfeiting and purchase intent for authentic products in experiments where I randomly assign exposure to counterfeit shoe stimuli across a sample of respondents.

The study uncovers the heterogeneous effects of counterfeits on the sales of branded products of three quality tiers among existing product lines. Specifically, counterfeits have both advertising effects for the brand and substitution effects for the authentic products. This finding supports previous studies that have shown negative and positive effects of imitation but also specifies more clearly the context in which a given effect will dominate. The advertising effect appears to dominate the substitution effect for high-end authentic products, as reflected in the finding of a net positive effect of counterfeiting on the sales of such goods. The substitution effect outweighs the advertising effect for low-end product sales, resulting in a net negative effect. The effects last for some years. Such differential effects reinforce incentives for authentic producers to innovate. For example, the results show that market shares for higher-quality products increases post-counterfeit-entry, while those of the lower-end products decline. I also show evidence for product-line proliferation after entry.

My experimental approach replicates similar heterogeneous effects on purchase intent related to high-, medium-, and low-tier branded products. These results suggest that counterfeits signal brand popularity to at least some consumers and that a large number of consumers prefer access to a variety of quality levels, further supporting the idea that counterfeits steal demand from low-end authentic products while demonstrating positive spillover effects for high-end authentic products. These findings substantiate and enrich the discovery in prior research (Qian 2008, 2011) that authentic firms' average prices and quality increase after entry by counterfeits. Combining these studies with the present one provides a deeper understanding of how counterfeit entry under weak intellectual property protection affects the innovation incentives of firms and markets. Moreover, the consistency of results from the Chinese field panel data and U.S.-based lab experiments demonstrate that the panel-based findings have implications beyond China.

I also identify heterogeneous effects of counterfeiting along other dimensions of brand and product. Notably, the positive spillover effects are larger for newer, less established brands and for brands that are less famous at the time of the infringement. The effects are also larger for products that are more fashion-driven in nature and those that are tailored to young customers. All these findings hint at 
the advertising effects of counterfeiting for the targeted brand and product. It is worth noting that this study disentangles the separate effects of the life stage of a brand and the quality tier within a brand portfolio. Within each brand type and product class, I again identify the counterfeiting effects at the quality-tier level through the difference-in-difference-in-difference simultaneous equation estimations.

In sum, this paper identifies the heterogeneous effects of counterfeits on authentic-product sales through a combination of field data and lab experiments. The findings have important policy and business implications. For example, New York Senator Charles Schumer introduced legislation in August 2010 that would rewrite copyright law to cover fashion design (Raustiala and Sprigman 2010), but he may not have had in mind the positive effect of imitations. Since this study demonstrates that counterfeits primarily hurt low-end authentic products and have positive net effects on high-end ones, the focus of enforcement against counterfeits should be directed toward low-quality counterfeits or counterfeits that steal business directly from authentic producers. It seems not only socially beneficial to weed out low-quality counterfeits and to keep certain levels of high-quality competition but also privately efficient for branded companies.

In addition, the findings that the positive sales impact of counterfeiting is more pronounced for brands that are not yet well known at the time of infringement could imply that trademarks and IPR may be optimally enforced at different stages of brand or product adoption cycles or through the use of a timing strategy. This is exactly what Microsoft did in China, by fiercely enforcing anti-piracy measures only after the majority of Chinese users had adopted its products (in either authentic or pirated form). In general, at the early stages of brand development, counterfeits could help boost brand awareness and market penetration, playing a role very similar to that of buzz agents. Strong brand awareness and familiarity may be required for positive thoughts and feelings toward the brand (Keller 2003), and counterfeiting helps to establish or enhance these prerequisites. This also links to findings that suggest that no publicity is bad publicity (Berger et al. 2010), since counterfeits generate publicity for the brand. As the brand grows in prominence, counterfeits' benefits dwindle, and authentic producers can enhance enforcement to curb the business-stealing effects of imitations.

Moreover, the present results suggest that brands need not concern themselves significantly with counterfeits that are of much lower quality than their authentic counterparts, since the low-quality imitations capture a very different customer segment that would not purchase the authentic product in the first place. Brands can also devote relatively fewer enforcement resources to high-fashion product lines and high-end lines designed for younger customers, as counterfeits can help set fashion trends and diffuse authentic innovation. This further promotes the product-innovation cycle.

Applications of the insights gained from this study go beyond the realm of counterfeits. For 
example, Qian et al. (2010) identify a positive spillover effect of a low-quality (but not counterfeit) entrant on an original brand using comprehensive scanner data from an American apparel company. Kuksov and Xie (2011) also theorize about the positive competition effect in the status goods market. The findings I present here, therefore, could be extended to these and similar contexts. The collective, growing body of research in this area suggests that IPR protection likely has an optimal level and that the optimum varies from country to country (Qian 2007 and 2009), sector to sector (Qian et al. 2012), brand to brand, and even product to product (type and quality levels). The optimum could also have a time dimension, given the life-stage effects discussed in this study. Thus, to drive optimal innovation and enforcement policies, business managers and policy makers should keep in mind that counterfeiters can be both foes and friends.

\section{REFERENCES}

Aghion, P., N. Bloom, R. Blundell, R. Griffith, and P. Howitt (2005), "Competition and Innovation: An inverted U relationship" The Quarterly Journal of Economics, CXX (2), 701-728.

American Apparel and Footwear Association (2005), ShoeStats, AAFA.

Anderson, E., Yi Qian, and D. Simester (2011), "Spillover Effects of a Low-quality Entrant," Working Paper, Northwestern University and MIT.

AQSIQ, Administration of Quality Supervision, Inspection and Quarantine (1991-2004), Year Books.

AQSIQ (2000), Guidelines for ISO Applications and Frequently Asked Questions.

Bate, Roger, Ginger Jin, and Aparna Mathur (2012), "Counterfeit or Substandard? Assessing Price and Non-Price Signals of Drug Quality," Working Paper.

Berger, J., A. Sorensen, and S. Rasmussen (2010), "Positive Effects of Negative Publicity," Marketing Science, 29(5), pp. 815827.

Berger, J. and Morgan Ward (2010), "Subtle Signals of Inconspicuous Consumption," Journal of Consumer Research, 37, 555-569.

Biais, B. and E. Perotti (2008), "Entrepreneurs and New Ideas," RAND Journal of Economics, Vol. 39, No. 4, Winter 2008 pp. 11051125.

Branstetter, Lee and Mariko Sakakibara (2002), "Do Stronger Patents Induce More Innovation? Evidence From the 1988 Japanese Patent Law Reforms." The American Economic Review, 92, 1, pp. $143-159$.

Branstetter, L., Fisman, R., and Foley, C. F. (2006), The Quarterly Journal of Economics, February 2006, 321-349.

Bresnahan, T., Shane Greenstein, and Rebecca Henderson (2010), "Schumpeterian Competition and Diseconomies of Scope: Illustrations from the Histories of Microsoft and IBM," Working Paper.

Castro, J., D. Balkin, and D. Shepherd (2008), "Can Entrepreneurial Firms Benefit From Product Piracy?" Journal of Business Venturing, 23 (1): 75-90.

Chinese National Bureau of Statistics (1995), Codebook for the Third Chinese National Industrial Census, National Bureau of Statistics. 
Cogitamus Consulting (2009), The Global Footwear Market: Athletic and non-Athletics Shoes, Packaged Facts. August 2009.

Conner, K.R. and Rumelt, R.P. (1991), "Software piracy: an analysis of protection strategies," Management Science, Vol. 37, February, pp. 125-39.

Fink, C., K. Maskus, and Y. Qian (2010), "The Economic Effects of Counterfeiting and Piracy," Advisory Committee on Enforcement WIPO 9/3/2010, World Intellectual Property Organization.

Gabriel, Satya J. (1998), "Is Banking Reform in China Still on Track?" Satya Gabriel's Online Papers: China Essay Series http://www.satya.us

Galloni, A. (2006), "Bagging Fakers and Sellers", Wall Street Journal, January 31, B1-2.

Gans, J. David Hsu, S. Stern (2008), "The Impact of Uncertain Intellectual Property Rights on the Market for Ideas: Evidence from Patent Grant Delays", Management Science, 54: 982-997.

Godes, D. and Dina Mayzlin (2009), "Firm-Created Word of Mouth Communication: Evidence from a Field Test" Marketing Science, Vol. 28:4, pp.721-739.

Gosline, R. (2009), "Simultaneous Distinction, Democratization and Omnivorism Effects: A Longitudinal Analysis of Dynamic Symbolic Boundaries in Counterfeit Consumption Networks," Dissertation, Harvard Business School.

Gosline, R. (2010), "Counterfeit Labels: Good For Luxury Brands?" Forbes, 2/12/2010.

Grossman, G. and Shapiro, C. (1988a), "Foreign Counterfeiting of Status Goods," Quarterly Journal of Economics, vol. 103, no. 412.

Grossman, G. and Shapiro, C. (1988b), "Counterfeit Product Trade", American Economic Review, 78, $59-75$.

Hong, S.-H. (2008), "Measuring the Effect of Napster on Recorded Music Sales," Manuscript available at https://netfiles.uiuc.edu/hyunhong/www/research.htm.

Hui, Kai-Lung and I.P.L. Png (2003), "Piracy and the Legitimate Demand for Recorded Music", Contributions to Economic Analysis and Policy, Vol. 2 No. 1, Article 11.

Jaffe, A. and Lerner, Josh (2004), Innovation and Its Discontents, Princeton University Press.

Keller, Kevin, "Brand Synthesis: The Multidimensionality of Brand Knowledge." Journal of Consumer Research, Vol 29, No. 4 (March 2003), p.595-600.

Khan, B.Z. (2004), "Does Copyright Piracy Pay? The Effects of U.S. International Copyright Laws on the Market for Books, 1790-1920", NBER Working Paper Series, 10271.

KPMG China (2010), "Refined Strategies: Luxury extends its reach across China", Consumer Markets 6(5): 37 .

Kuksov, D. and Y. Xie (2011), "Competition in a Status Good Market," Working Paper.

Kyle, Margaret and Anita McGahan (2011), "Investments in Pharmaceuticals Before and After TRIPS," Review of Economics and Statistics. March.

Lerner, J. (2009), "The Empirical Impact of Intellectual Property Rights on Innovation: Puzzles and Clues," American Economic Review: Papers 83 Proceedings, 99:2, 343348.

Li, Ye, Yan Zhang, and Ting Zhu (2011), "How Multiple Anchors Affect Judgment? Evidence from the Lab and eBay." University of Chicago Working Paper.

Liebowitz, S. J. (2006), "Economists Examine File-Sharing and Music Sales," in Industrial Organization and the Digital Economy, eds. G. Illing and M. Peitz. Cambridge: MIT Press, 145-174.

Lin, Jessica (2011), Fake Stuff. Routledge, Taylor \& Francis, New York. 
Luo, L., J. Chen, J. Han, and C. Park (2010), "Dilution and Enhancement of Celebrity Brands through Sequential Movie Releases, Journal of Marketing Research, Vol.47, No.6, 1114-1128.

Mortimer, J. and J. H., C. Nosko, and A. Sorensen (2010), "Supply Responses to Digital Distribution: Recorded Music and Live Performance," forthcoming, Information Economics and Policy.

Murray F. and S. Stern (2007), "Do formal Intellectual Property Rights Hinder the Free Flow of Scientific Knowledge?" Journal of Economic Behavior and Organization, Vol. 63:4, p.648-687.

Naughton, Barry (2002), "China's Economic Think Tanks: Their Changing Role in the 1990s," The China Quarterly, V.171, Cambridge University Press, Sep..

Oberholzer-Gee, Felix and Koleman Strumpf (2007), "The Effect of File Sharing on Record Sales: An Empirical Analysis," Journal of Political Economy, 115:1.

- (2009), "File-Sharing and Copyright". Innovation Policy and the Economy series, volume 10. ed. Joshua Lerner and Scott Stern. MIT Press. 2009.

Piller, C. (2006), "How Piracy Opens Doors for Windows", Los Angeles Times, April, 9, http://articles.latimes.com/2006/apr/09/business/fi-micropiracy9.

Qian, Yi (2007), "Do National Patent Laws Stimulate Domestic Innovation In A Global Patenting Environment? A Cross-Country Analysis of Pharmaceutical Patent Protection: 1978-2002" Review of Economics and Statistics, 89:3. MIT Press.

Qian, Yi (2008), "Impacts of Entry by Counterfeiters," Quarterly Journal of Economics, November 2008, Vol. 123, No. 4: 15771609. MIT Press.

Qian, Yi (2010), "Brand Management and Strategies Against Counterfeits," forthcoming, Journal of Economics and Management Strategy.

Qian, Yi and Jie Chen (2011), "Cross-culture Experiments on Counterfeits." Northwestern University Working Paper.

Qian, Yi and Xie, Hui (2011), "No Customer Left Behind - A Distribution-Free Bayesian Approach to Accounting for Missing Xs in Marketing Models," with Hui Xie, Marketing Science, August 2011.

Qian, Yi and Xie, Hui (2013), "Which Customers are Lost to the Counterfeiters?" Northwestern University Working Paper.

Qian, Yi and Victor Shih (2010), "Code Book for Board of Directors of Chinese Firms," Memo, http:

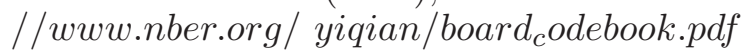

Raustiala, K. and C. Sprigman (2009), "Piracy Paradox", Virginia Law Review, Vol. 92, p. 1687.

Raustiala, K. and C. Sprigman (2010), "Why Imitation is the Sincerest Form of Fashion", The New York Times, Aug. 12, 2010.

Rob, Rafael and Joel Waldfogel (2006), "Piracy on the High Cs: Music Downloading, Sales Displacement, and Social Welfare in a Sample of College Students," Journal of Law and Economics, Vol. XLIX, April, p.29-62.

Schmidle, N. (2010), "Inside the Knockoff-Tennis-Shoe Factory," The New York Times, Aug. 19, 2010.

Thursby, M., R. Jensen, and J. Thursby (1991), "Smuggling, Camouflaging, and Market Structure," Quarterly Journal of Economics, Vol. 106, No. 3 (Aug., 1991), pp. 789-814, Oxford University Press.

Wilcox, K., H. Kim, and S. Sen (2009), "Why Do Consumers Buy Counterfeit Luxury Brands?” Journal of Marketing Research, Vol. 46 (April), 24759.

Wild, Joff (2007), "The Truth about Trademarks in China," World Trademark Review, January/February, 2007. 
Table 1. Political Connections and Average Counterfeiting Occurrences By Brand

Notes: This table tabulates the average number of ISO certification days and the average sales quantities of counterfeits for each of the 31 brands in the sample.

\begin{tabular}{|c|c|c|}
\hline Brand & \# ISO Days & The Sales Quantity of Counterfeits \\
\hline 1 & 31 & $\begin{array}{ll}2.20 & 0\end{array}$ \\
\hline 2 & 31 & 14 \\
\hline 3 & 31 & 51 \\
\hline 4 & 46 & 0 \\
\hline 5 & 49 & 126 \\
\hline 6 & 65 & 27 \\
\hline 7 & 65 & 75 \\
\hline 8 & 78 & 0 \\
\hline 9 & 86 & 14 \\
\hline 10 & 95 & 75 \\
\hline 11 & 102 & 27 \\
\hline 12 & 107 & 0 \\
\hline 13 & 114 & 146 \\
\hline 14 & 115 & 60 \\
\hline 15 & 120 & 0 \\
\hline 16 & 144 & 0 \\
\hline 17 & 146 & 96 \\
\hline 18 & 169 & 62 \\
\hline 19 & 172 & 184 \\
\hline 20 & 172 & 135 \\
\hline 21 & 199 & 96 \\
\hline 22 & 204 & 41 \\
\hline 23 & 214 & 197 \\
\hline 24 & 214 & 145 \\
\hline 25 & 224 & 40 \\
\hline 26 & 249 & 161 \\
\hline 27 & 259 & 111 \\
\hline 28 & 264 & 160 \\
\hline 29 & 276 & 220 \\
\hline 30 & 289 & 146 \\
\hline 31 & 303 & 221 \\
\hline
\end{tabular}


Table 2: Summary Statistics Before and After the Policy Change

\begin{tabular}{|c|c|c|}
\hline Variable: & Pre-1995 & Post-1995 \\
\hline Percentage of Government Resources in & .11 & .02 \\
\hline Monitoring Footwear Trademarks & $(.004)$ & $(.001)$ \\
\hline Workdays Authentic Company Took to Pass ISO & 142 & 149 \\
\hline (Relationship Proxy) & $(116.5)$ & $(112.6)$ \\
\hline Experience matches between brand managers & 3.11 & 3.36 \\
\hline and AQSIQ Officials & $(3.79)$ & $(3.83)$ \\
\hline Experience matches between product managers & 4.98 & 5.11 \\
\hline and AQSIQ Officials & $(2.16)$ & $(2.14)$ \\
\hline \multirow[t]{2}{*}{ Incorporation Year of Authentic Brands } & 1985 & 1985 \\
\hline & $(11)$ & $(11)$ \\
\hline \multirow[t]{2}{*}{ Number of Company Stores } & 0 & 684 \\
\hline & $(0)$ & $(533.5)$ \\
\hline Authentic Brand-Protection Office Personnel & .17 & 4.0 \\
\hline (Head count) & $(.46)$ & $(2.23)$ \\
\hline \multicolumn{3}{|l|}{ Quantity (in 10,000 pairs) } \\
\hline$\overline{\text { Fake Sale Quantity }}$ & Median 0 & $\begin{array}{l}85.71 \\
(75.85)\end{array}$ \\
\hline Authentic Sale Quantity & $\begin{array}{l}309.38 \\
(725.76)\end{array}$ & $\begin{array}{l}558.28 \\
(995.82)\end{array}$ \\
\hline \multicolumn{3}{|l|}{ Prices, Costs, and other Numerairs (Deflated, in USD) } \\
\hline Fake Shoe Price & $\begin{array}{l}\text { Median } 0 \\
(8.33 \text { to } 10.4)\end{array}$ & $\begin{array}{l}7.32 \\
(4.2)\end{array}$ \\
\hline Fake Shoe Costs & $\begin{array}{l}\text { Median } 0 \\
(2.2 \text { to } 3.56)\end{array}$ & $\begin{array}{l}2.66 \\
(1.56)\end{array}$ \\
\hline Average Authentic Price of Existing Product Lines & $\begin{array}{l}26.21 \\
(13.64)\end{array}$ & $\begin{array}{l}32.24 \\
(20.45)\end{array}$ \\
\hline Average Authentic Costs of Existing Product Lines & $\begin{array}{l}22.61 \\
(12.90)\end{array}$ & $\begin{array}{l}25.18 \\
(18.43)\end{array}$ \\
\hline Average Authentic Price of New Product Lines & & $\begin{array}{l}45.37 \\
(26.06)\end{array}$ \\
\hline Average Authentic Costs of New Product Lines & & $\begin{array}{l}35.47 \\
(24.37)\end{array}$ \\
\hline Self-enforcement Costs of Authentic Brands & $\begin{array}{l}520 \\
(1550)\end{array}$ & $\begin{array}{l}81380 \\
(83140)\end{array}$ \\
\hline Advertising Expenditure & $\begin{array}{l}1496700 \\
(2724200)\end{array}$ & $\begin{array}{l}2381500 \\
(3329300)\end{array}$ \\
\hline Real GDP per capita PPP & $\begin{array}{l}310.25 \\
(5.57)\end{array}$ & $\begin{array}{l}488.13 \\
(2.83)\end{array}$ \\
\hline No. of Obs. & 62 & 310 \\
\hline
\end{tabular}

This table presents the summary statistics of the brand-level dataset, slicing it into two parts: data prior to the year 1995, when the Chinese government reallocated enforcement resources away from the footwear sector to fill in the needs of the safety sectors, and data after 1995. Each row reports the means and standard deviations (in parentheses) of a variable in the two time lines. The range statistics for the counterfeit shoe prices and costs report the ranges of the corresponding values when counterfeits existed for some brands. It was rather sparse before the policy shift. The percentage of government resources devoted to monitoring the shoe sector is obtained from the Quality and Technology Supervision Bureau. Real GDP per capita PPP is obtained from the World Bank World Development Indicators (WDI). Prices and costs are deflated using the Consumer Price Index published in the WDI (Year 1995 was set as the base year in the database). 
Table 3: First-stage IV Regression

\begin{tabular}{lllll}
\hline Dependent Variable: & \multicolumn{3}{c}{ Fake Entry } \\
\cline { 2 - 4 } & $(1)$ & $(2)$ & $(3)$ & $(4)$ \\
\hline Loose & $.72^{* *}$ & & \\
& $(.04)$ & & \\
Relation proxied by ISO & & .11 & & .11 \\
(scaled by dividing 100) & & $(.13)$ & & $(.12)$ \\
Relation proxied by Biographic Match & & & .08 & .09 \\
& & & $(.06)$ & $(.08)$ \\
Loose*ISO & & & $.33^{* *}$ \\
& & $(.01)$ & & $(.06)$ \\
Loose*Bio-match & & & $.13^{* *}$ & $.14^{* *}$ \\
& & & $(.03)$ & $(.03)$ \\
Year trend & $(.0002)$ & & & \\
& No & Yes & Yes & Yes \\
Year Fixed Effects & 372 & 372 & 5833 & 5833 \\
No. of Obs. & .00 & .00 & .00 & .00 \\
p-values & & & \\
\hline
\end{tabular}

This table reports the first stage of IV estimations. All models use brand-fixed effects. The counterfeit entry dummy (equals one if counterfeits are discovered for a brand) and log of deflated authentic product prices are regressed on the set of I.V., with the year trend and company fixed effects, in four separate regressions. Each column reports one regression specification. Heteroskedasticity-consistent standard errors that correct for clustering at the company level appear in parentheses. Statistical significance levels: ${ }_{-}^{*} 5 \%$; ${ }^{*}{ }_{-}-1 \%$. Columns 1 to 4 present alternative first-stage IV specifications to show robust significant relationship between the set of IVs and the entry of counterfeits. The variables are: Loose - a dummy indicating enforcement legislation change, which equals 1 in 1995 onwards; ISO - relationship between the brand and the QTSB, as proxied by the number of work days between the application and grant dates of ISO certificate for an authentic company; Loose*ISO - interaction between legislation change and a company's relationship with the government; Biographic matches an 1-10 scaled variable that is constructed based on the education and experience matches between the brand and product-line managers and that of the AQSIQ officials; Loose*Bio-match - interaction between legislation change and the biographic-match variable. 
Table 4. IV Regression Results for Log Sale Quantity of Three Fixed Quality Tiers

Notes: This table reports five regression specifications. Point estimates (standard errors) are reported in the first (second) row aligning with the corresponding independent variable. Standard Errors are clustered at the productline level. Year trend is used in order to obtain the estimates on the macroeconomic variables. "**” and “**” denote statistical significance at the 0.05 and 0.01 levels, respectively.

Variable

OLS pooled

(1)

IV pooled High-end

Medium-end

Low-end

Entry

(2)

(3)

(4)

(5)

High-end

$0.31^{*} \quad 0.49 *$

Medium-end

$-0.27 *$

$-0.16$

Low-end

(0.12)

(0.15)

$-0.94 * *$

$-0.75 * *$

$\ln ($ price)

(0.15)

(0.20)

In(Ads)

$-0.19 *$

$-0.19 *$

(0.09)

(0.10)

$0.22 *$

0.23 *

(0.11)

(0.12)

Age

0.01

0.01

(0.01)

(0.02)

In(household

3.66

4.26

consumption)

(2.38)

(2.27)

Economic growth

0.02

$-0.01$

(0.02)

(0.02)

Consumption per

GDP

$-0.02$

$-0.03 *$

(0.01)

(0.01)

Gini coefficient

0.01

0.08

(0.04)

Female shoes

$0.52^{* *}$

(0.06)

(0.03)

$0.42^{* *}$

$0.46 *$

$-0.23$

$-0.57^{*}$

(0.22)

(0.18)

(0.23)

High-leg boots
Medium-leg boots
Slippers
Sport shoes
Constant
Year Trend
Brand and product-line FE
Tier FE
Year Trend*Tier
$\mathrm{N}$

$-1.41^{* *}-1.43^{* *}$

(0.05)

(0.05)

$-0.98 * * \quad-0.99 * *$

(0.04)

(0.03)

$-1.55^{* *}$

$-1.54 * *$

(0.05)

(0.05)

$1.27^{* *}$

$1.53^{* *}$

(0.26)

(0.22)

$-11.67 *$

$-10.98^{*}$

(4.95)

(4.87)

\begin{tabular}{|c|c|c|}
\hline-0.11 & -0.18 & -0.26 \\
\hline (0.19) & $(0.15)$ & $(0.16)$ \\
\hline $0.27^{*}$ & 0.21 & 0.13 \\
\hline$(0.14)$ & (0.17) & (0.19) \\
\hline 0.01 & 0.00 & 0.00 \\
\hline$(0.01)$ & $(0.01)$ & $(0.02)$ \\
\hline 0.45 & $3.11^{*}$ & $5.87^{* *}$ \\
\hline (0.67) & (1.45) & $(1.12)$ \\
\hline $0.08^{*}$ & -0.06 & $-0.15^{* *}$ \\
\hline$(0.04)$ & $(0.04)$ & $(0.05)$ \\
\hline 0.05 & -0.05 & $-0.18 * *$ \\
\hline$(0.03)$ & $(0.04)$ & $(0.04)$ \\
\hline 0.06 & $0.23 * *$ & $0.39 * *$ \\
\hline$(0.07)$ & $(0.08)$ & $(0.10)$ \\
\hline $0.18^{*}$ & $0.56 * *$ & $0.47^{* *}$ \\
\hline$(0.08)$ & $(0.09)$ & $(0.10)$ \\
\hline$-1.38 * *$ & $-1.52^{* *}$ & $-1.62 * *$ \\
\hline$(0.11)$ & $(0.14)$ & $(0.16)$ \\
\hline$-0.96 * *$ & $-1.03^{* *}$ & $-1.08 * *$ \\
\hline$(0.05)$ & $(0.06)$ & $(0.09)$ \\
\hline$-1.51 * *$ & $-1.47^{* *}$ & $-1.61 * *$ \\
\hline$(0.08)$ & $(0.07)$ & $(0.09)$ \\
\hline $0.81 * *$ & $1.32 * *$ & $1.56^{* *}$ \\
\hline$(0.31)$ & $(0.30)$ & $(0.33)$ \\
\hline $15.28^{*}$ & -7.21 & $-12.39 *$ \\
\hline$(6.92)$ & (7.82) & $(5.52)$ \\
\hline$Y$ & $Y$ & $Y$ \\
\hline$Y$ & $Y$ & $Y$ \\
\hline $\mathrm{N}$ & $\mathrm{N}$ & $\mathrm{N}$ \\
\hline $\mathrm{N}$ & $\mathrm{N}$ & $\mathrm{N}$ \\
\hline 1944 & 1945 & 1944 \\
\hline
\end{tabular}


Table 5. Robustness Analyses with More Control Covariates and Natural Clusters of Quality Tiers Notes: This table reports six regression specifications based on data resulting from natural clustering. Point estimates (standard errors) are reported in the first (second) row aligning with the corresponding independent variable. Standard Errors are clustered at the product-line level. Year trend is used in order to obtain the estimates on the macroeconomic variables. “*” and “**” denote statistical significance at the 0.05 and 0.01 levels, respectively.

\begin{tabular}{|c|c|c|c|c|c|c|}
\hline Variable & $\begin{array}{l}\text { Cluster C } \\
\text { (1) }\end{array}$ & $\begin{array}{l}\text { High-end } \\
\text { (2) }\end{array}$ & $\begin{array}{c}\text { Medium } \\
\text { (3) }\end{array}$ & $\begin{array}{l}\text { Low-end } \\
\text { (4) }\end{array}$ & $\begin{array}{l}\text { Interact C } \\
\text { (5) }\end{array}$ & $\begin{array}{l}\text { Cluster P } \\
\text { (6) }\end{array}$ \\
\hline Entry & & $\begin{array}{l}0.51^{* *} \\
(0.19)\end{array}$ & $\begin{array}{l}-0.12 \\
(0.21)\end{array}$ & $\begin{array}{l}-0.71^{* *} \\
(0.28)\end{array}$ & & \\
\hline High-end & $\begin{array}{r}0.58 * * \\
(0.16)\end{array}$ & & & & $\begin{array}{r}0.40 * * \\
(0.13)\end{array}$ & $\begin{array}{r}0.56^{* *} \\
(0.18)\end{array}$ \\
\hline Medium-end & $\begin{array}{r}-0.01 \\
(0.15)\end{array}$ & & & & $\begin{array}{r}0.01 \\
(0.14)\end{array}$ & $\begin{array}{r}0.37 \\
(0.29)\end{array}$ \\
\hline Low-end & $\begin{array}{r}-0.48 * * \\
(0.18)\end{array}$ & & & & $\begin{array}{r}-0.57 * * \\
(0.14)\end{array}$ & $\begin{array}{r}-0.65 * * \\
(0.23)\end{array}$ \\
\hline $\ln ($ price) & $\begin{array}{c}-0.23^{*} \\
(0.11)\end{array}$ & $\begin{array}{l}-0.17 \\
(0.21)\end{array}$ & $\begin{array}{l}-0.20 \\
(0.19)\end{array}$ & $\begin{array}{r}-0.28 \\
(0.19)\end{array}$ & $\begin{array}{c}-0.32 * \\
(0.12)\end{array}$ & $\begin{array}{r}-0.26^{* *} \\
(0.10)\end{array}$ \\
\hline $\ln ($ Ads) & $\begin{array}{r}0.21 \\
(0.12)\end{array}$ & $\begin{array}{r}0.28 \\
(0.15)\end{array}$ & $\begin{array}{r}0.22 \\
(0.17)\end{array}$ & $\begin{array}{r}0.18 \\
(0.17)\end{array}$ & $\begin{array}{l}0.26^{*} \\
(0.12)\end{array}$ & $\begin{array}{r}0.22 \\
(0.12)\end{array}$ \\
\hline Age & $\begin{array}{r}0.00 \\
(0.01)\end{array}$ & $\begin{array}{r}0.01 \\
(0.02)\end{array}$ & $\begin{array}{r}0.00 \\
(0.02)\end{array}$ & $\begin{array}{r}0.01 \\
(0.01)\end{array}$ & $\begin{array}{r}0.00 \\
(0.00)\end{array}$ & $\begin{array}{r}0.01 \\
(0.01)\end{array}$ \\
\hline $\begin{array}{l}\text { In(household } \\
\text { consumption) }\end{array}$ & $\begin{array}{r}3.17 \\
(1.82)\end{array}$ & $\begin{array}{r}0.24 \\
(0.87)\end{array}$ & $\begin{array}{c}3.56^{*} \\
(1.38)\end{array}$ & $\begin{array}{l}4.27^{*} \\
(2.12)\end{array}$ & & $\begin{array}{r}2.98 \\
(1.76)\end{array}$ \\
\hline Economic growth & $\begin{array}{r}-0.03 \\
(0.03)\end{array}$ & $\begin{array}{l}0.08 * \\
(0.03)\end{array}$ & $\begin{array}{r}-0.08 * * \\
(0.03)\end{array}$ & $\begin{array}{r}-0.11^{*} \\
(0.04)\end{array}$ & & $\begin{array}{r}0.02 \\
(0.02)\end{array}$ \\
\hline $\begin{array}{l}\text { Consumption per } \\
\text { GDP }\end{array}$ & $\begin{array}{l}-0.02 \\
(0.02)\end{array}$ & $\begin{array}{r}-0.06 \\
(0.04)\end{array}$ & $\begin{array}{r}0.04 \\
(0.05)\end{array}$ & $\begin{array}{r}-0.03 \\
(0.04)\end{array}$ & & $\begin{array}{l}-0.01 \\
(0.03)\end{array}$ \\
\hline WTO Accession & $\begin{array}{r}-0.04 \\
(0.04)\end{array}$ & $\begin{array}{r}-0.02 \\
(0.05)\end{array}$ & $\begin{array}{l}-0.07 \\
(0.06)\end{array}$ & $\begin{array}{l}-0.14^{*} \\
(0.07)\end{array}$ & & $\begin{array}{r}-0.05 \\
(0.04)\end{array}$ \\
\hline Gini coefficient & $\begin{array}{r}0.05 \\
(0.04)\end{array}$ & $\begin{array}{r}-0.08 \\
(0.08)\end{array}$ & $\begin{array}{r}0.13 \\
(0.09)\end{array}$ & $\begin{array}{r}0.43 * * \\
(0.14)\end{array}$ & & $\begin{array}{r}0.07 \\
(0.06)\end{array}$ \\
\hline Female shoes & $\begin{array}{r}0.47^{* *} \\
(0.04)\end{array}$ & $\begin{array}{r}0.36 * * \\
(0.07)\end{array}$ & $\begin{array}{r}0.36 * * \\
(0.06)\end{array}$ & $\begin{array}{r}0.35^{* *} \\
(0.08)\end{array}$ & $\begin{array}{r}0.48 * * \\
(0.10)\end{array}$ & $\begin{array}{r}0.52^{* *} \\
(0.06)\end{array}$ \\
\hline High-leg boots & $\begin{array}{r}-1.51 * * \\
(0.08)\end{array}$ & $\begin{array}{r}-1.51 * * \\
(0.12)\end{array}$ & $\begin{array}{r}-1.44 * * \\
(0.14)\end{array}$ & $\begin{array}{r}-1.4^{* *} \\
(0.12)\end{array}$ & $\begin{array}{r}-1.51 * * \\
(0.07)\end{array}$ & $\begin{array}{r}-1.40 * * \\
(0.07)\end{array}$ \\
\hline Medium-leg boots & $\begin{array}{r}-0.98 * * \\
(0.03)\end{array}$ & $\begin{array}{r}-1.13^{* *} \\
(0.04)\end{array}$ & $\begin{array}{r}-1.02 * * \\
(0.04)\end{array}$ & $\begin{array}{l}-1.0 * * \\
(0.06)\end{array}$ & $\begin{array}{r}-0.98 * * \\
(0.04)\end{array}$ & $\begin{array}{r}-0.96 * * \\
(0.03)\end{array}$ \\
\hline Slippers & $\begin{array}{r}-1.46 * * \\
(0.05)\end{array}$ & $\begin{array}{r}-1.57 * * \\
(0.06)\end{array}$ & $\begin{array}{r}-1.53 * * \\
(0.06)\end{array}$ & $\begin{array}{l}-1.6 * * \\
(0.07)\end{array}$ & $\begin{array}{r}-1.46 * * \\
(0.05)\end{array}$ & $\begin{array}{r}-1.53 * * \\
(0.05)\end{array}$ \\
\hline Sport shoes & $\begin{array}{r}1.52 * * \\
(0.13)\end{array}$ & $\begin{array}{r}1.37^{* *} \\
(0.28)\end{array}$ & $\begin{array}{r}1.98^{* *} \\
(0.19)\end{array}$ & $\begin{array}{r}1.11 * * \\
(0.21)\end{array}$ & $\begin{array}{r}1.52 * * \\
(0.11)\end{array}$ & $\begin{array}{r}1.46 * * \\
(0.23)\end{array}$ \\
\hline Constant & $\begin{array}{r}-8.67 \\
(5.12)\end{array}$ & $\begin{array}{r}14.71 * * \\
(6.45)\end{array}$ & $\begin{array}{r}-4.41 \\
(6.53)\end{array}$ & $\begin{array}{r}-10.79 \\
(8.43)\end{array}$ & $\begin{array}{l}4.98^{*} \\
(2.12)\end{array}$ & $\begin{array}{r}-7.58 \\
(4.73)\end{array}$ \\
\hline Year Trend & $\mathrm{Y}$ & $\mathrm{Y}$ & $\mathrm{Y}$ & $\mathrm{Y}$ & $\mathrm{Y}$ & $\mathrm{Y}$ \\
\hline Brand and line FE & Y & Y & Y & Y & Y & Y \\
\hline Tier FE & $Y$ & $\mathrm{~N}$ & $\mathrm{~N}$ & $\mathrm{~N}$ & $Y$ & Y \\
\hline YearTrend*Tier & $Y$ & $\mathrm{~N}$ & $\mathrm{~N}$ & $\mathrm{~N}$ & $\mathrm{~N}$ & $\mathrm{Y}$ \\
\hline YearTrend*Brand*Tier & $\mathrm{N}$ & $\mathrm{N}$ & $\mathrm{N}$ & $\mathrm{N}$ & $Y$ & $\mathrm{~N}$ \\
\hline $\mathrm{N}$ & 5833 & 1518 & 2099 & 2216 & 5833 & 5833 \\
\hline
\end{tabular}


Table 6. Stratification Analyses on the Mechanisms of the Positive Spillover Effects

Notes: This table reports six regression specifications to test the mechanism of the positive spillover effects of counterfeiting. The moderating factors (M) are: 1 . Whether the product is highly fashionable (dress shoes and tall-leg women boots) or not; 2. Whether the brand was not classified as a "renowned brand" at the time of infringement; 3. Whether the brand was not listed as "China Famous Brands" at the time of the infringement; 4 . Whether the brand is relatively new, whose age is below the median; 5 . Whether the brand has a single brand; 6 . Whether the products were designed more for younger customers. Point estimates (standard errors) are reported in the first (second) row aligning with the corresponding independent variable. Standard Errors are clustered at the product-line level. Year trend is used in order to obtain the estimates on the macroeconomic variables. "*” and “**” denote statistical significance at the 0.05 and 0.01 levels, respectively.

\begin{tabular}{|c|c|c|c|c|c|c|}
\hline Variable & $\begin{array}{c}\text { fashion } \\
\text { (1) }\end{array}$ & $\begin{array}{c}\text { nonrenown } \\
\text { (2) }\end{array}$ & $\begin{array}{c}\text { nonfamous } \\
\text { (3) }\end{array}$ & $\begin{array}{c}\text { newbrand } \\
\text { (4) }\end{array}$ & $\begin{array}{c}\text { onebrand } \\
\text { (5) }\end{array}$ & $\begin{array}{c}\text { user-age } \\
\text { (6) }\end{array}$ \\
\hline \multicolumn{7}{|l|}{$\mathrm{E}^{*} \mathrm{M}$} \\
\hline \multirow[t]{2}{*}{ High-end } & $0.37^{*}$ & $0.46^{*}$ & $0.33^{*}$ & $0.51^{*}$ & $0.48^{*}$ & $0.37^{*}$ \\
\hline & $(0.17)$ & $(0.21)$ & $(0.16)$ & $(0.24)$ & $(0.22)$ & $(0.15)$ \\
\hline \multirow[t]{2}{*}{ Medium-end } & 0.46 & 0.39 & 0.21 & -0.29 & $-0.36 *$ & -0.35 \\
\hline & (0.19) & (0.19) & $(0.20)$ & $(0.18)$ & $(0.17)$ & $(0.18)$ \\
\hline \multirow[t]{2}{*}{ Low-end } & 0.12 & 0.21 & 0.16 & $-0.85^{* *}$ & $0.63^{*}$ & $0.46 *$ \\
\hline & $(0.24)$ & $(0.25)$ & (0.19) & $(0.27)$ & $(0.23)$ & $(0.18)$ \\
\hline \multicolumn{7}{|l|}{ Entry (E) } \\
\hline \multirow[t]{2}{*}{ High-end } & $0.39 *$ & $0.23^{*}$ & $0.35^{*}$ & 0.16 & 0.27 & $0.29 *$ \\
\hline & $(0.16)$ & $(0.12)$ & $(0.13)$ & $(0.13)$ & $(0.17)$ & $(0.13)$ \\
\hline \multirow[t]{2}{*}{ Medium-end } & $-0.33^{*}$ & -0.24 & -0.22 & -0.04 & 0.19 & -0.13 \\
\hline & $(0.17)$ & $(0.16)$ & $(0.19)$ & $(0.15)$ & (0.14) & $(0.18)$ \\
\hline \multirow[t]{2}{*}{ Low-end } & $-0.78 * *$ & $-0.89 * *$ & $-0.82 * *$ & $-0.38^{*}$ & $-1.01 * *$ & $-1.09 * *$ \\
\hline & $(0.21)$ & $(0.21)$ & $(0.17)$ & $(0.16)$ & $(0.18)$ & $(0.26)$ \\
\hline \multicolumn{7}{|l|}{ Moderator (M) } \\
\hline \multirow[t]{2}{*}{ High-end } & $0.14^{*}$ & -0.23 & -0.45 & $-0.54^{*}$ & $-1.22^{*}$ & 0.42 \\
\hline & $(0.06)$ & $(0.81)$ & $(0.33)$ & $(0.23)$ & $(0.47)$ & $(0.22)$ \\
\hline \multirow[t]{2}{*}{ Medium-end } & 0.02 & $0.98 * *$ & -0.37 & -0.14 & -0.53 & 0.06 \\
\hline & (0.19) & $(0.20)$ & $(0.36)$ & $(0.37)$ & $(0.52)$ & (0.09) \\
\hline \multirow[t]{2}{*}{ Low-end } & -0.72 & -0.17 & $-4.67 *$ & $2.13^{* *}$ & $-2.35 * *$ & -0.62 \\
\hline & $(1.28)$ & $(1.07)$ & (1.19) & $(0.81)$ & $(0.82)$ & $(1.01)$ \\
\hline \multirow[t]{2}{*}{ In(price) } & $-0.21^{*}$ & $-0.19 *$ & $-0.18^{*}$ & -0.18 & $-0.20 *$ & $-0.19 *$ \\
\hline & $(0.11)$ & $(0.10)$ & $(0.09)$ & $(0.10)$ & $(0.10)$ & $(0.10)$ \\
\hline \multirow[t]{2}{*}{$\ln ($ Ads) } & 0.21 & $0.22 *$ & $0.25^{*}$ & 0.20 & 0.20 & $0.24^{*}$ \\
\hline & $(0.12)$ & $(0.11)$ & $(0.12)$ & $(0.13)$ & $(0.13)$ & $(0.12)$ \\
\hline \multirow[t]{2}{*}{ age } & 0.01 & 0.00 & 0.01 & 0.01 & 0.01 & 0.01 \\
\hline & $(0.01)$ & $(0.01)$ & $(0.01)$ & $(0.02)$ & $(0.01)$ & $(0.01)$ \\
\hline \multirow[t]{2}{*}{ Economic growth } & 0.03 & 0.03 & 0.02 & 0.02 & 0.03 & 0.01 \\
\hline & $(0.02)$ & $(0.02)$ & $(0.02)$ & $(0.02)$ & $(0.02)$ & $(0.02)$ \\
\hline \multirow{2}{*}{$\begin{array}{l}\text { log(household } \\
\text { consumption) }\end{array}$} & 2.67 & 2.85 & 2.75 & 2.66 & 2.69 & 2.71 \\
\hline & $(1.73)$ & $(1.58)$ & $(1.58)$ & $(1.63)$ & $(1.52)$ & $(1.71)$ \\
\hline \multirow[t]{2}{*}{ Consumption per GDP } & -0.03 & -0.02 & 0.01 & -0.03 & $-0.04 *$ & -0.04 \\
\hline & $(0.02)$ & $(0.02)$ & $(0.02)$ & $(0.02)$ & $(0.02)$ & $(0.03)$ \\
\hline \multirow[t]{2}{*}{ Gini coefficient } & $0.07 * *$ & $0.06 * *$ & $0.07 * *$ & $0.06 * *$ & $0.04 * *$ & $0.08 * *$ \\
\hline & $(0.02)$ & $(0.02)$ & $(0.02)$ & $(0.02)$ & $(0.01)$ & $(0.02)$ \\
\hline
\end{tabular}




\begin{tabular}{|c|c|c|c|c|c|c|}
\hline Female shoes & $\begin{array}{r}0.51^{* *} \\
(0.03)\end{array}$ & $\begin{array}{r}0.50 * * \\
(0.03)\end{array}$ & $\begin{array}{r}0.51^{* *} \\
(0.03)\end{array}$ & $\begin{array}{r}0.48^{* *} \\
(0.03)\end{array}$ & $\begin{array}{r}0.51^{* *} \\
(0.03)\end{array}$ & $\begin{array}{r}0.51^{* *} \\
(0.03)\end{array}$ \\
\hline High-leg boots & $\begin{array}{r}-1.46 * * \\
(0.04)\end{array}$ & $\begin{array}{r}-1.44 * * \\
(0.04)\end{array}$ & $\begin{array}{r}-1.47^{* *} \\
(0.04)\end{array}$ & $\begin{array}{r}-1.44^{* *} \\
(0.05)\end{array}$ & $\begin{array}{r}-1.46^{* *} \\
(0.05)\end{array}$ & $\begin{array}{r}-1.46 * * \\
(0.05)\end{array}$ \\
\hline Medium-leg boots & $\begin{array}{r}-0.86 * * \\
(0.04)\end{array}$ & $\begin{array}{r}-0.86 * * \\
(0.04)\end{array}$ & $\begin{array}{r}-0.95^{* *} \\
(0.04)\end{array}$ & $\begin{array}{r}-0.91 * * \\
(0.04)\end{array}$ & $\begin{array}{r}-0.90^{* *} \\
(0.04)\end{array}$ & $\begin{array}{r}-0.99 * * \\
(0.04)\end{array}$ \\
\hline Slippers & $\begin{array}{r}-1.53 * * \\
(0.05)\end{array}$ & $\begin{array}{r}-1.53 * * \\
(0.05)\end{array}$ & $\begin{array}{r}-1.52^{* *} \\
(0.05)\end{array}$ & $\begin{array}{r}-1.53^{* *} \\
(0.05)\end{array}$ & $\begin{array}{r}-1.52 * * \\
(0.05)\end{array}$ & $\begin{array}{r}-1.47 * * \\
(0.07)\end{array}$ \\
\hline Sport shoes & $\begin{array}{r}1.49 * * \\
(0.20)\end{array}$ & $\begin{array}{r}1.48^{* *} \\
(0.20)\end{array}$ & $\begin{array}{r}1.51^{* *} \\
(0.19)\end{array}$ & $\begin{array}{r}1.48^{* *} \\
(0.20)\end{array}$ & $\begin{array}{r}1.60 * * \\
(0.21)\end{array}$ & $\begin{array}{r}1.55^{* *} \\
(0.21)\end{array}$ \\
\hline Year Trend & $Y$ & $Y$ & Y & $Y$ & $Y$ & $Y$ \\
\hline Brand- and line-FE & $Y$ & $Y$ & $Y$ & $\mathrm{Y}$ & $Y$ & $Y$ \\
\hline Tier FE & Y & $Y$ & Y & $Y$ & Y & Y \\
\hline YearTrend*Tier & $Y$ & $Y$ & $Y$ & $\mathrm{Y}$ & $Y$ & $Y$ \\
\hline $\mathrm{N}$ & 5833 & 5833 & 5833 & 5833 & 5833 & 5833 \\
\hline
\end{tabular}


Figure 1. Bar Chart of the Percentage Sales Pre- and Post-Entry by Quality Tiers

Note: This figure presents the percentage sales breakdown of the product-line level dataset, slicing it into two parts: data prior to the year that the corresponding brand was infringed by its counterfeits and the data after that. All company-level data are gathered through original interviews and surveys. Existing product lines refer to those that existed throughout the sample period, while new product lines refer to those that were added one to three years after the brands were infringed by counterfeits.

a. Overall Breakdowns of Three Quality Tiers

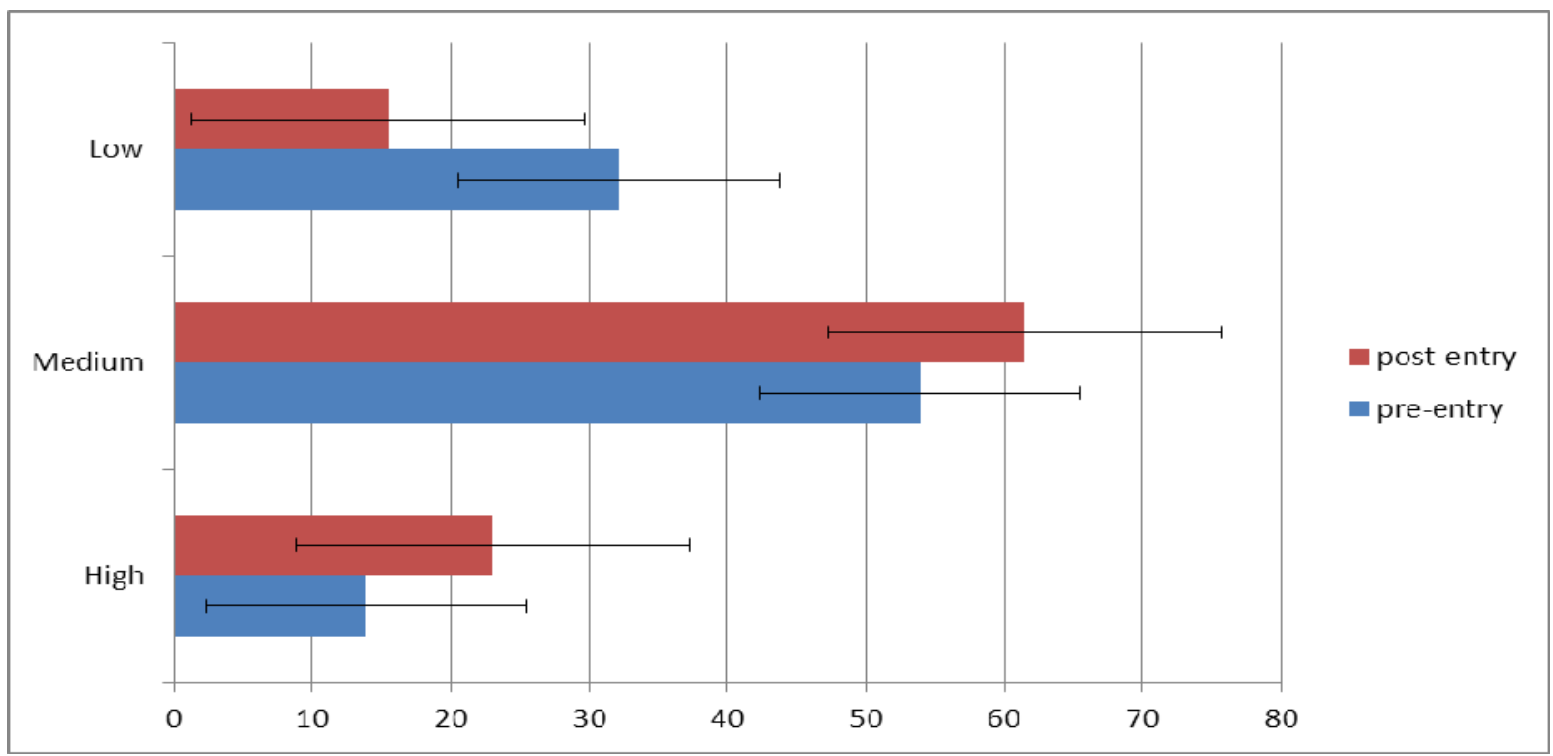

b. Breakdown by Existing Product Lines and New Product Lines, Each of Three Quality Tiers

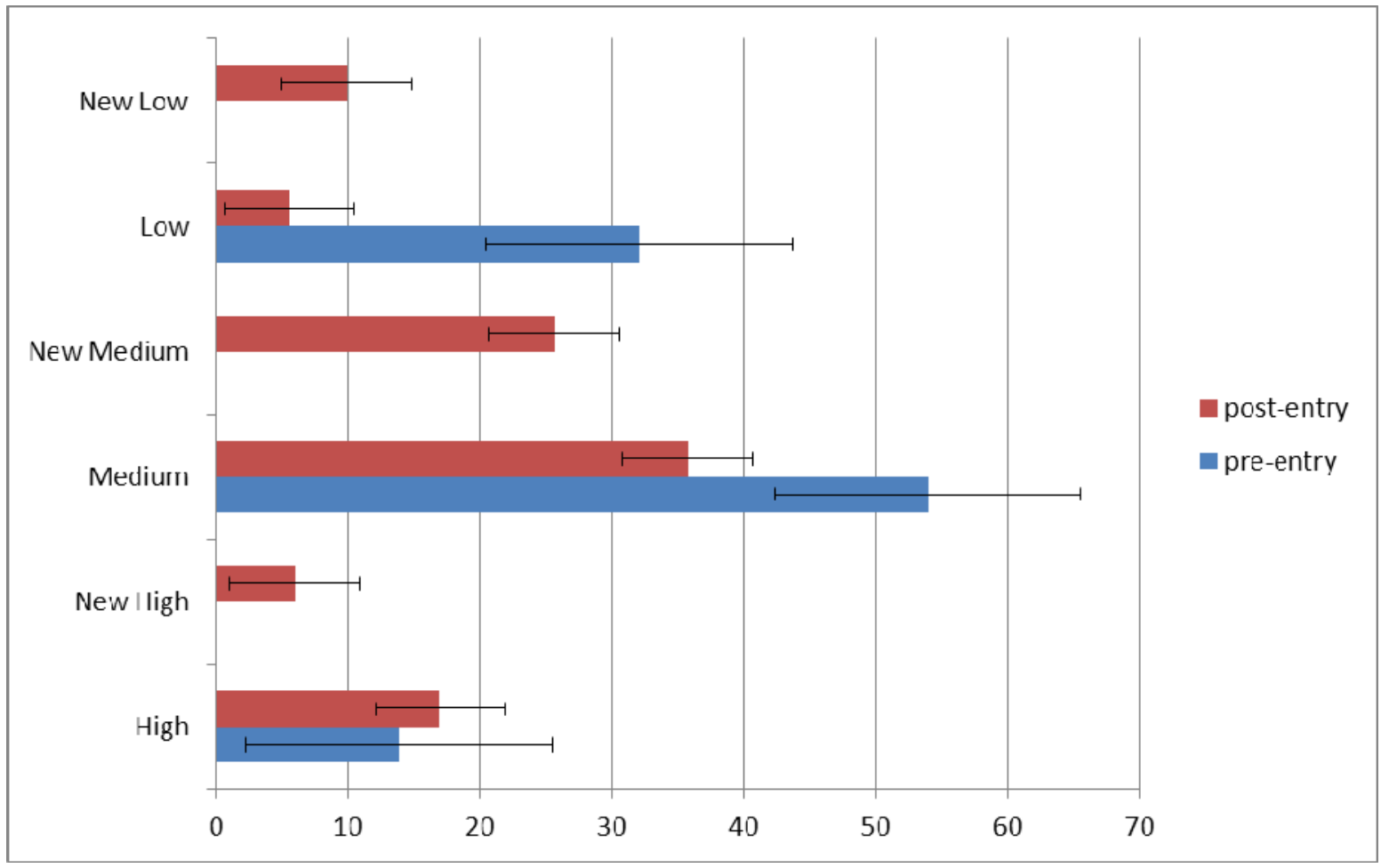


Figure 2a. Box Plots of the Distributions of the Product-type-adjusted Deflated Unit Production Cost Across Manufacturers' Quality Tiers

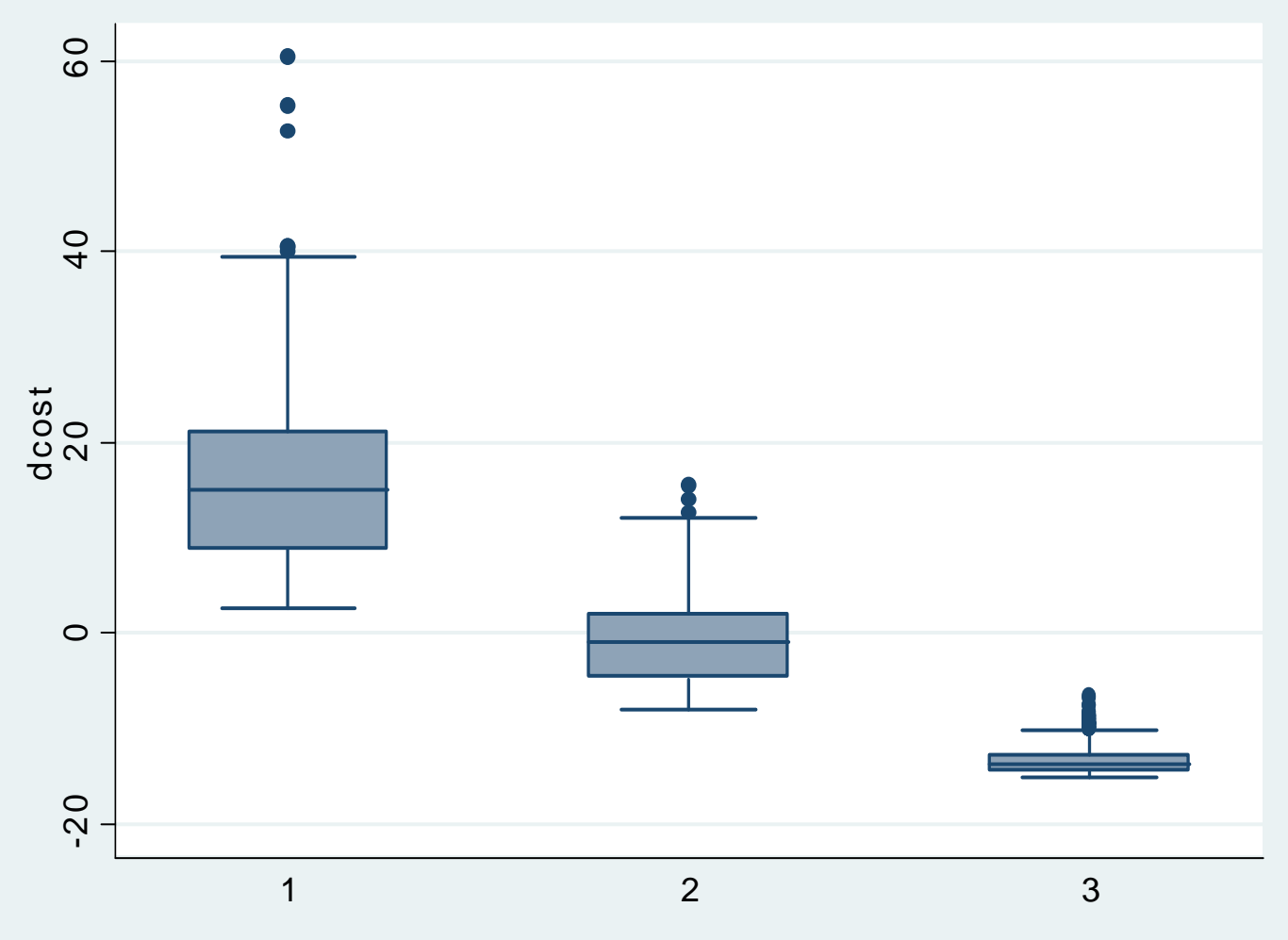

Figure 2b. Box Plots of the Distributions of the Product-type-adjusted Deflated Unit Production Cost Across Quality Tiers by Natural Clustering

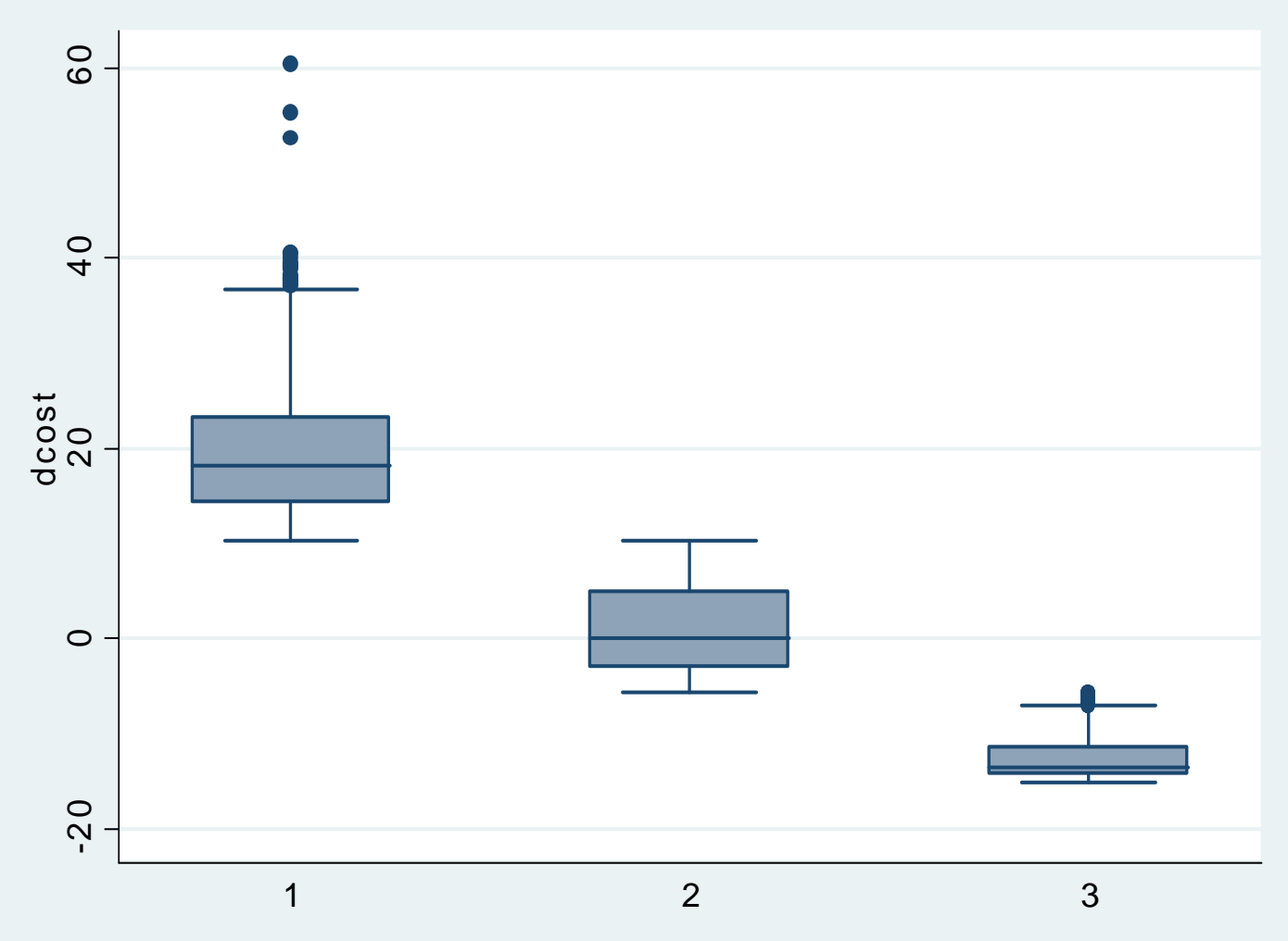


Figure 3: Coefficient Trend of Log Sale Quantity against Years Relative to Entry for the Existing Product Lines

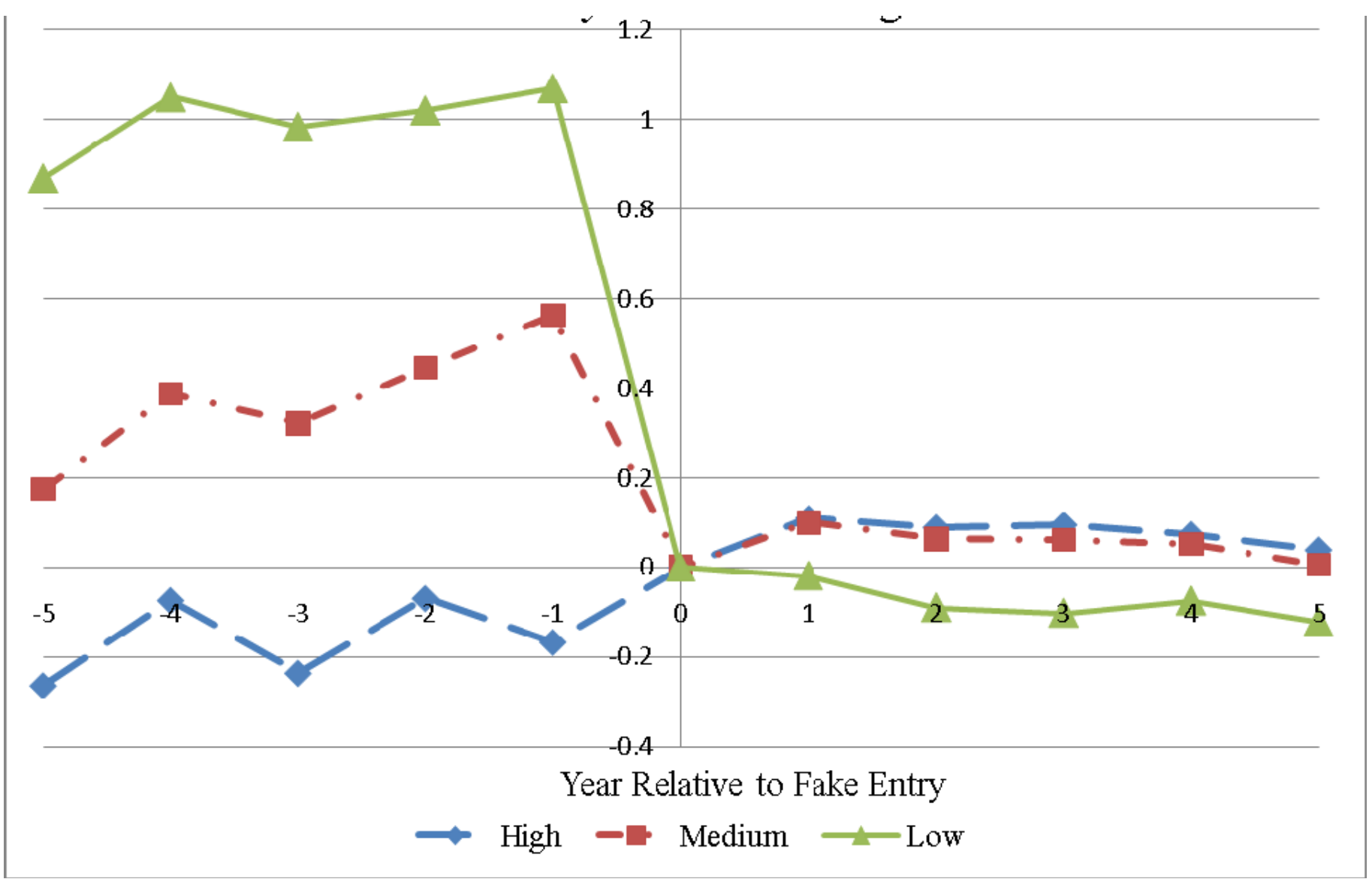

Figure 4: Coefficient Trend of Log Sale Quantity Against Years Relative to Entry for the New Product Lines

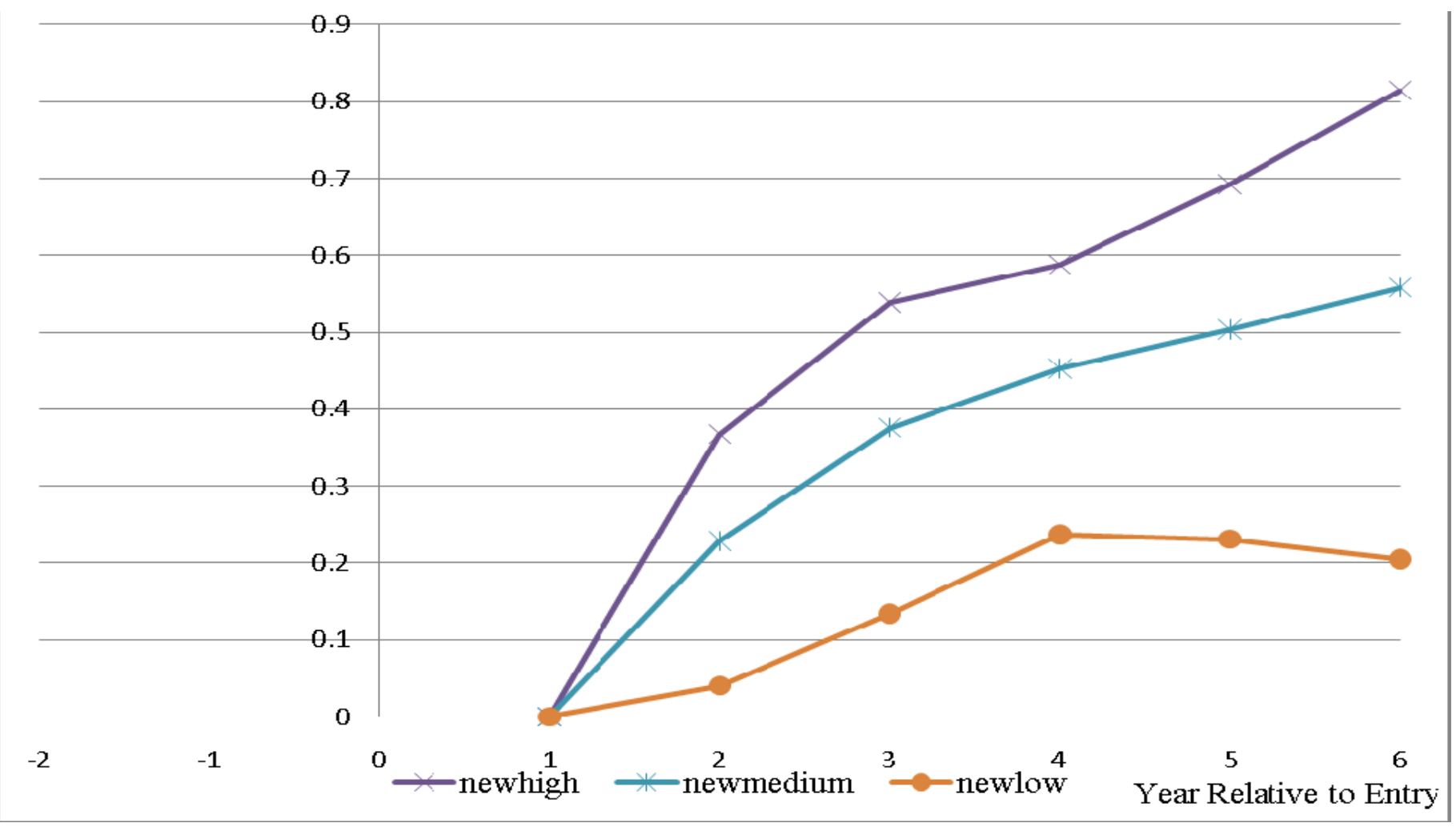

